\title{
Language and the Sensing Body: How Sensoriality Permeates Syntax in Interaction
}

\author{
Lorenza Mondada ${ }^{* t}$ \\ Department of Linguistics and Literature, University of Basel, Basel, Switzerland
}

\section{OPEN ACCESS}

Edited by:

Leelo Keevallik,

Linköping University, Sweden

Reviewed by:

Tiina Keisanen,

University of Oulu, Finland

Giovanni Rossi,

University of California, Los Angeles,

United States

*Correspondence:

Lorenza Mondada

lorenza.mondada@unibas.ch

tORCID ID:

Lorenza Mondada

orcid.org/0000-0002-7543-9769

Specialty section:

This article was submitted to

Language Sciences,

a section of the journal

Frontiers in Communication

Received: 05 February 2021

Accepted: 19 July 2021

Published: 22 December 2021

Citation:

Mondada L (2021) Language and the Sensing Body: How Sensoriality

Permeates Syntax in Interaction.

Front. Commun. 6:664430.

doi: $10.3389 /$ fcomm.2021.664430
This article explores the grammar-body interface by examining the intertwinement of embodied practices and turns at talk, where the sensing body permeates the ongoing syntax, in particular in activities in which the participants are engaged in talking about sensorial features while at the same time experiencing them, for instance in tasting sessions. So, the question tackled concerns how situated feelings, sensory experiences, and perceptive actions are embedded in the ongoing talk, and how they shape its emergent syntax, possibly affecting its smooth progressivity. The study shows how the choice of specific syntactic formats can be systematically related to the complex ecology of embodied actions, namely to publicly accountable ways of sensing material objects, to ways of showing and addressing an audience, and to visible ways of referring to standard documents normatively defining tasting descriptors. The syntactic formats described and their specific temporal realizations are thus deeply rooted in the local material ecology, in which they not only reproduce a normative model but reflexively express the senses with words and sensuously feel the words.

Keywords: conversation analysis, social interaction, syntax, multimodality, multisensoriality, looking, showing, touching

\section{INTRODUCTION}

The grammar-body interface in social interaction has been explored in multiple ways, demonstrating how the organization of turns at talk is tightly articulated with the organization of embodied conducts (Keevallik 2018a) not only within co-occurring gesture and lexical affiliates (Schegloff 1984; Kendon 2004) or the gaze management of turns and sequences (Goodwin 1981; Rossano 2012b) but also within "complex multimodal gestalts" (Mondada 2014a). A basic configuration that has attracted the attention of interactional linguists and conversation analysts concerns the articulation between grammatical constructions and gesture/gaze/other embodied movements (see, for example, Goodwin 1981; Hayashi 2005; Ford et al., 2012; Deppermann 2013a). Beside these kinds of gestalts, however, other forms of articulation have been less explored: they concern cases in which the body "irrupts" into talk (Keevallik and Ogden 2020), such as when sounds of effort (Keevallik 2018b) or pain (Heath 1989) and other "response cries" (Goffman 1978) manifest within the ongoing turn, when emotions intervene in talk (such as laughter, Jefferson 1985; crying, Hepburn 2004; sobbing, Weatherall 2021). More radically, they also concern forms of multiactivity (Haddington et al., 2014), where embodied activities concurrent with talking activities permeate talk and modify its trajectories, projections, and progressivity.

This article is interested in these articulations between body manifestations and syntactic arrangements and examines a particular type of intertwinement of embodied practices and turns 
at talk, where the sensing body and the ongoing syntax are accountably intertwined, in particular in activities in which the participants are engaged in talking about sensorial features while at the same time experiencing them. So, the question tackled concerns how situated feelings, sensory experiences, and perceptive actions are embedded in the ongoing talk and how they affect its emergent syntax. Reversely, the question is also how grammar accommodates these contingencies and embeds them in its malleable order-especially when they can be exploited in service of warranting the epistemic authority, expertise, and accountability of the ongoing action and of its doer.

This article emanates from an interest in describing the methodic order of linguistic formats that refer to its in vivo and in situ production embedded in complex activities in which talk might be an important aspect but not the only activity going on. The issue is whether it is at all possible to propose a grammar in interaction that takes into account complex ecologies of action, and if yes, how this is possible. The proposal made here, building on insights first introduced by Goodwin (1981), is that it is indeed crucial to describe language in relation to its natural habitat, that is, within situated, embodied activities emmeshed in local material ecologies that constrain and support their detailed organization. The way linguistic formats adjust to these conditions reveals the indexical nature of grammar.

These issues will be discussed on the basis of an exemplary setting that exhibits them: a series of workshops in which an expert trains professional cheese tasters. In this setting, the participants engage in an activity focused on the description of the relevant sensorial features of the sample they are examining. The setting is exemplary in the sense that it enables a description of how turns are linguistically formatted in a context in which the speaker is deeply involved in embodied actions. This shows not only the necessity of taking into consideration the multimodal formatting of turns and actions, but more radically it shows how linguistic formats can be understood only if related to their local material praxeological context. In particular, I show how apparently simple syntactic formats can only be understood in their complexity when examining the global embodied sensorial and institutional activity of the participants; I also show how within this perspective, it is also possible to account for alternative choices, selecting that simple format versus syntactically more elaborated constructions.

In the previous literature, the embeddedness of talk within other activities, in which talk is neither the main nor the prioritized course of action, has been discussed in terms of multiactivity (Haddington et al., 2014). The concept refers to the fact that one or more participants can be engaged in several activities at the same time: this generates several courses of action that unfold simultaneously and are mutually adjusted, which affects their detailed emergent and contingent temporality in a crucial way. These praxeological configurations are made possible by a distribution of available multimodal resources in time, typically with some courses of action privileging talk and others privileging embodied conducts. Diverse modes of organization have been discussed in this respect, in which talk can be subordinated to other embodied activities, or the reverse. For example, in operating on a patient while demonstrating the operation to medical students, the surgeon can alternatively prioritize the temporal order of the surgical procedure or the temporal order of the talk, diversely adjusting one to the other (Mondada 2011; 2014b). Contexts in which people talk while doing something else are legion (Haddington et al., 2014): a good example is having a conversation while driving (Goodwin and Goodwin 2012; Mondada 2012; Nevile 2018). In this article, I specifically focus on activities in which a participant verbally explains, describes, or demonstrates something they are doing. This configuration has been studied in various contexts, in which, for instance, a caretaker announces or instructs the ongoing massage on a client (Nishizaka 2016), a doctor comments in real time on the echography of a pregnant woman (Nishizaka 2014), surgeons explain how they are operating (Mondada 2014b), dance teachers demonstrate dance steps to trainees (Keevallik 2013,2014), coaches show good and bad postures in sport activities (Evans and Reynolds 2016; Råman and Haddington 2018), trainers teach postures in self-defense courses (Stukenbrock 2017), a cook demonstrates how to prepare a dish to novices (Mondada 2014c), etc. These studies have shown how language and the body are deeply intertwined in the temporal organization of these complex activities and how the temporality of embodied actions can be at moments prioritized over the temporality of talk, or vice versa, their relations depending not only on local contingencies but also on the way the participants reflexively shape their action as more or less permeable and adjustable to them. In this sense, studies of multiactivity have complexified the vision of multimodality by showing how embodied and linguistic resources can contribute not only to format a single action but also several actions at the same time. One consequence of the latter case is that the arrangement of resources and their temporality is adjusted to concurrent courses of actions. In this article, I deal with another setting for demonstrations, in which the focus is on the sensorial practices of the participants, who engage at the same time in sensing and formulating what they sense. These demonstrations are a perspicuous setting to reflect on a perspective on syntax drawing on multiactivity. It also enables a discussion of the relation between body and language in terms of the articulation between grammar, and more particularly syntax, and sensoriality.

While research on sensoriality is just emerging in ethnomethodology, conversation analysis, and interactional linguistics (Mondada 2019a, 2021), it has a firmly established tradition in psycholinguistics and cognitive sciences (Levinson and Majid 2014; Majid 2021). In the former, the in situ sensory practices and the conditions for producing descriptions of sound, visual, haptic, olfactory, or tasting features in embodied activities of sensing are the focus (Liberman 2013; Mondada 2018a, 2018b, Fele 2019; Mondada 2020a; Mondada 2020b, 2021). In the latter, the main focus is on the lexical forms that subjects produce when sensing some sample within an elicitation task. Tasting 
vocabularies are produced not only by psycholinguists studying them but also by sensory sciences within a normative perspective, aiming at standardizing and controlling the production of sensory objects of consumption (Drake and Civille 2003). Although there are considerable discussions about the types of lexical forms subjects use (not only adjectives but also metaphors and similitudes, typically when they lack specific sensorial vocabularies, like for describing smell, Majid 2021), the syntactical format used for responding to the eliciting questions (such as What kind of color/sound/smell is this?) is never considered in the analyses. Thus, the grammar of taste (as well as of the other senses) is mainly described in terms of a lexicon, focusing on the resultant outcome of the sensorial experience in controlled tasks but not in terms of the syntax in which this lexicon is embedded. Moreover, the embodied experience of sensing itself, which precedes the verbal outcome, does not constitute an object of study (it is sometimes described a priori, in normative terms, as it has been planned within the methodology). By contrast, the study of sensorial practices in naturalistic settings, for example in tasting sessions, enables consideration of both how the embodied experience is actually formatted and how its outcomes are verbally produced, including their temporality, format, and sequential position within the ongoing activity (Mondada 2018a for taste, 2018b for vision, 2020a for smell, $2020 \mathrm{~b}$ for smell and touch, as well as 2021 for an overall conceptualization).

Within the interactional literature, the syntax of turn formats has been described in a variety of actions and environments. Some studies have addressed the issue of how these formats relate to embodied activities. For instance, in the literature about assessments (Pomerantz 1984; Goodwin and Goodwin 1987), the reference to the assessable and the format of the assessing clause have been discussed, in particular in relation to the ingestion of food (in dinner conversations, Wiggins 2002; Mondada 2009; Wiggins 2014; or in semi-experimental settings, Gomezalez Temer 2017). However, tasting sessions differ from ordinary eating activities in the sense that they aim at producing descriptors of taste, which are predicated on the tasted objects rather than assessments, which instead express a subjective judgment of the taster (cf. Wiggins and Potter 2003). In other contexts, the formatting of requests has been discussed in relation to embodied co-occurring actions: the selection by speakers of Noun phrase (NP) formats vs. clauses for requests in Finnish shop encounters has been discussed by Sorjonen and Raevaara (2014) in relation to the timing of the speakers' embodied movements approaching the counter. The selection between imperatives vs. interrogative constructions including a turn-initial dative pronoun $m i$ "to/for $m e^{\text {" for }}$ requests in Italian is discussed by Rossi (2012), differentiating between requests embedded in an ongoing joint embodied activity and unilateral requests enlisting assistance in new self-contained projects benefitting the individual requester. More broadly, the relation between turn formatting, its emergent syntax, and embodied actions has been discussed in terms of multiple temporal trajectories in Deppermann and Streeck (2018).
This article focuses on how participants organize their embodied sensorial access and experiences to the materiality at hand and on the syntactic formats in which they express their resulting descriptions. This casts light not only on the grammarbody interface but also on embodiment, sensoriality, and language considered in the actual in vivo emergent temporality of multimodal and multisensorial practices.

\section{Data and Method}

The data studied in this article are video-recorded workshops in which an expert is training future professional tasters of cheese. The workshops were held in Trento (Italy) in 2017 (video recording of one entire day) and in Bellinzona (Switzerland) in 2018 (video recordings of 2 sessions of $3 \mathrm{~h}$ each). Participants were speaking northern regional varieties of Italian. In all the cases, the experts were members of the Organizzazione Nazionale degli Assaggiatori di Formaggio (ONAF), practicing the same techniques of tasting. The sessions have been video recorded by Giolo Fele and myself in Trento (see Mondada and Fele 2020) and by myself (Mondada 2020b) in terms of the articulation between grammar and more in Bellinzona. Several cameras and microphones were used with the informed consent of the trainees and the organizers. Participants also accepted that we collected the written instructions and materials distributed to the trainees as well as collecting some of their notes.

The workshops include demonstrations of sensing practices in the form of collective tasting sessions, recurrently organized in two parts: the first part is publicly focused on the expert holding and showing a piece of cheese in front of the trainees, demonstrating how to describe it. This description concerns the exterior aspects of the cheese as well as the visual and textural features of its paste. In the second part, concerning thickness, aroma, and taste, the participants receive individual samples, which they touch, smell, and taste under the guidance of the expert. In this article, I focus on the former, concerning the visual and haptic phases of the tasting procedure, which is demonstrated by the expert talking and exhibiting the relevant features in front of an audience of participants (ca 20-30 persons).

Besides experiencing the cheese with all their senses, the participants also engage in reading and writing activities. They can rely on various documents distributed at the beginning of the workshop, including tasting sheets and terminological lists containing the official categories and descriptors, ordered along the steps of the procedure (first the visual exam, then the haptic, olfactory, and tasting examinations). Some of these documents are also projected on a screen by the expert. During the session, the participants take notes and fill in the tasting sheet. The activities in which the participants engage during these sessions are therefore multiple and complex: they involve, on the one hand, the sensorial exploration of a material object and, on the other hand, an array of semiotic tools. The former is linguistically expressed using the latter; the latter shape not only the possibility of describing but also the possibility of sensing the former within a reflexive relationship in which language and sensoriality shape each other. 
Therefore, this activity is exemplary for studying how language, materiality, and sensoriality are intertwined within referential and sensorial practices mobilizing talk and the body. In this article, in particular, I focus on the way in which linguistic descriptions are produced and syntactically formatted in this context, showing how grammar is intimately embedded within bodily experiences, which are, in turn, deeply shaped by the institutional context in which they occur.

The data are studied within an ethnomethodological and conversation analytic perspective interested in the multimodal formatting of actions in their specific context (Streeck et al., 2011; Deppermann 2013b; Mondada 2014a; Keevallik 2018a) as well as in the engagement of the body in multisensorial experiences (Mondada 2019b, 2021). More specifically, the analysis deals with the way the complex actions of the expert demonstrating tasting are made accountable in situ. These actions are formatted by the expert, who, at the same time, engages with the materiality at hand, refers to the semiotic resources available, and addresses them to the copresent audience in a recipient-designed way. The article shows how the choice of syntactic formats-from the simplest nonclausal $\mathrm{N}$ + Adj format $(\$ 3)$ and its expansion $(\$ 4)$ to copular clauses $(\$ 5)$ and syntactically more complex formulations $(\$ 6)$-is intimately related to these multiple activities. It shows how syntactical choices are related to ongoing engagements in embodied activities, are made accountable by them, and in turn are reflexively made meaningful.

\section{The Simplest Syntactic Format: $\mathbf{N}+$ Adj}

Within the video-recorded tasting sessions, a recurrent format for describing the sample is $\mathrm{N}+$ Adj without any article or verb. The aim of this section is to pinpoint the multimodal organization of this minimal gestalt. In Extract 1, some occurrences verbally transcribed following the conventions of Jefferson (2004):

At a first glance, these formats are striking for their simplicity and also for their specific temporality and prosody. The initial $\mathrm{N}$ (in the absence of any article, which normally precedes the $\mathrm{N}$ in Italian syntax) is produced as an autonomous prosodic unit; moreover, it is followed by a pause, often relatively long. After the pause, at least one Adj is produced, morphologically marked by its gender agreement with the $\mathrm{N}$ (e.g., the $\mathrm{N}$ "forma" is feminine, and the Adj "cilindrica" is feminine too in contrast with "cilindrico" masculine), which confirms that the $\mathrm{N}$ and the Adj are part of the same structure. Here the Adj follows the $\mathrm{N}$ in its predicative use (vs. the alternative order also attested in Italian, which, however, is not predicative). This simple format is clearly bipartite (with a noticeable pause between $\mathrm{N}$ and Adj) and contrasts both with a bare NP (such as "forma cilindrica"/"cylindric form") and with a complete copular clause ("la forma è cilindrica"/"the form is cylindric"), which would imply the use of the article. The former is almost absent in the corpus, and the second will be discussed below as contrastively occurring in specific environments.

The situated production of this simple nonclausal format $\mathrm{N}+$ Adj shows that its accountability crucially relies on the embodied conduct of the speaker. The next extract (Extract 2) offers a multimodal transcript (following the conventions of Mondada 2018a; Mondada 2018b) of Extract 1B.

Prior to the description (2), the expert looks at the sample, first its face (Figure 1), then its side (Figure 2): he silently manipulates the object, visually inspecting it. When he begins to utter "forma,"/"shape," he directs his gaze to the audience

(1)

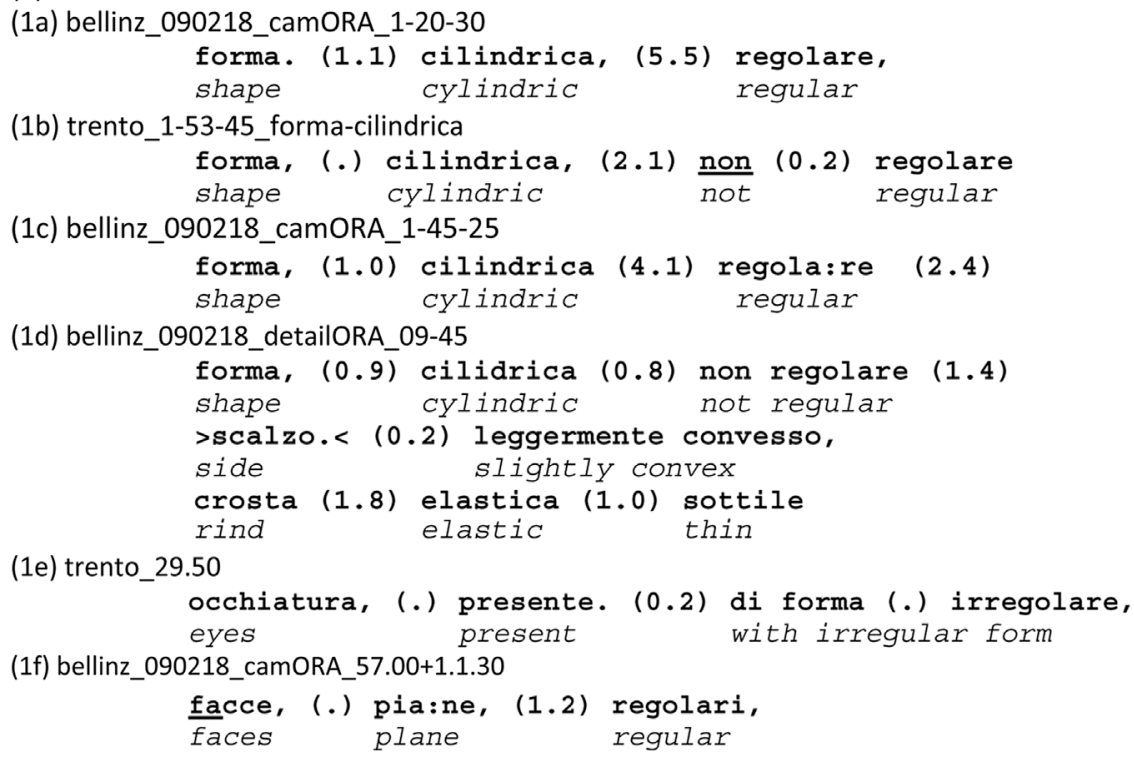

EXTRACT 1 | Visual descriptions of tasted cheeses. 
(Figure 3). The description (2) is uttered by holding the sample in his hands. Subsequently, the expert raises it while uttering the connective "allora"/"so" (Figure 4) and shows it to the audience, asking for their confirmation (Figures 5, 6). In this case, the action of the expert is organized in three moments: first, his visual inspection is made silently, then his description is addressed to the audience, and finally it is followed by a visual exhibition of the sample. The activity is thus organized around the successive visual access to the object by the expert and the audience. The publicly witnessable sensorial access of the expert to the object, while manipulating it, builds the public accountability and authority of his description as resulting from it. In turn, the description is a way to instruct the shared vision that the audience is given of the object. Thus, the description is multimodally formatted in a way that crucially relies on actions of looking and showing, building in situ the intersubjectivity of vision. The description is grounded in the orchestration of the sensorial access to the described object for all the participants.

So, the multimodal format of the expert's turn relies on a double embodied relation to the object described and to the audience to whom the description is addressed. But this is not all; another crucial aspect intervenes and accounts for the specific linguistic format used. This is observable in Extract 3, in which another expert deals with the same descriptor in another session.
Prior to looking at the cheese (1) and then describing it (2) while showing it to the audience (Figure 7), the expert looks at his computer (1, Figure 6). On his monitor, which is projected on a full screen for all the participants, there is a series of superposed visualizations: in the background is the empty tasting sheet that the participants have to fill in (Document 1), and in the foreground (in black, Document 2) is a list of descriptors corresponding to a list that has been distributed to the participants (Document 3). The list in black includes a series of links that can be activated to access further specifications (in white). Thus, looking at the computer screen, the expert accesses a structured lexicon for the description that is made accessible for the participants and corresponds to a complete terminology list they have on their tables.

The look at the computer screen (1) indexes the relation between the official terminology for professional tasters and the description to come. In this case, it points to the first feature to be considered when engaging in the external examination of the cheese, "forma"/"shape," followed by the selection of one possible descriptor among others, "cilindrica/"cylindric" (Document 3). This initial look and its visibility in the local ecology (where participants can see the look and the slides looked at) provides for the accountability of the verbal turn "forma, (1.0) cilindrica (4.1) regolare" as the product of a selection from the official terminology that is adequate for the object at hand. The syntactic format, in its simplicity,

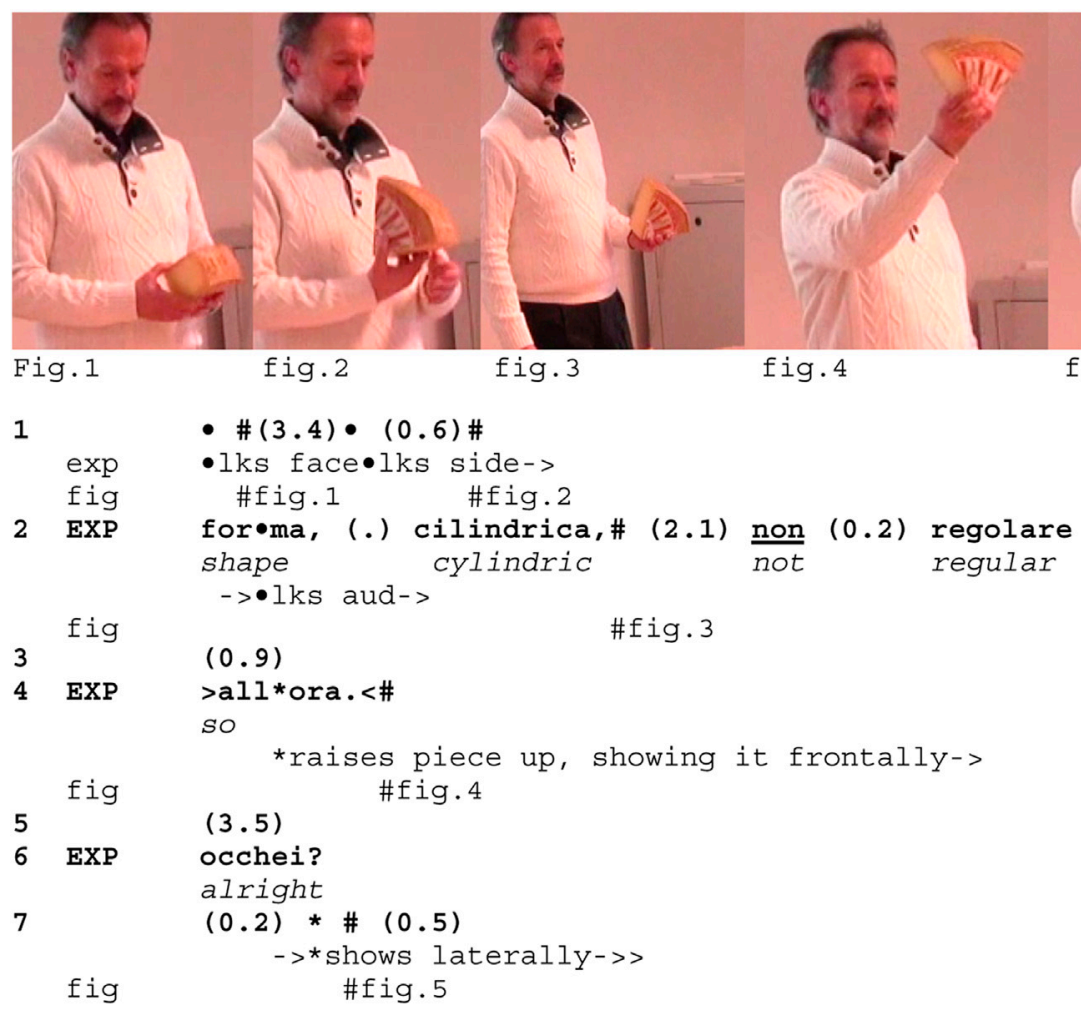

EXTRACT 2 | (2) trento_1-53-45 (cf. 1b supra). 
fig

$2 \operatorname{EXP}$
$\#(1.5) \cdot(0.5)$

>looks PC•looks cheese->

$\#$ fig. 6

forma, * (1.0) cilindrica (4.1) regola:\#re *(2.4)

shape cylindric

*raises

$\mathrm{ch}$

fig
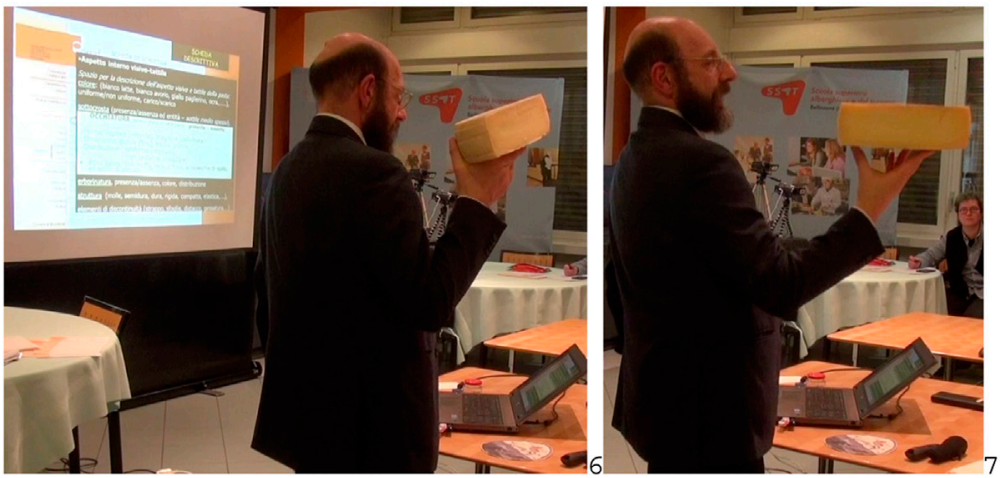

EXTRACT 3 | (3) bellinz_090218_camORA_1-45-25.

without any article or verb, precisely indexes the conformity of the description (and the object) to the preexisting terminology.

But the multimodal turn format does much more: the expert silently inspects the cheese before beginning to utter a description, thus displaying the latter as grounded in the former. The description is recipient-oriented since he raises the cheese form, showing it to the audience while uttering the two adjectives "cilindrica" and "regola:re" (2). By so doing, he provides for the audience with the opportunity to hear the descriptor while at the same time seeing the features described. In this way, the description is warranted by the sensorial access of the expert, and it makes reflexively possible a shared sensorial understanding by the audience.

Thus, the performance of the expert uttering the syntactic format $\mathrm{N}+$ (pause)+Adj is a multimodal and multisensorial one. Its complexity is observable in a more extended fragment, Extract $\mathbf{4}$, in which the categories of shape, faces, side, rind, and surface are described:

The expert produces the first description (1) by looking at the cheese, holding it at the level of his eyes (Figure 8): this enables him at the same time to inspect it, to make publicly visible his inspection, and to make the object visually accessible for the audience. Moreover, the description is exhibited-and warranted-as the result of not only sight but also touch (Figure 9). For "facce"/“faces" (2), the expert looks at the cheese during the long pause of $3.9 \mathrm{~s}$, making a circular gesture that indexes some difficulty or some resulting approximation, and then runs his finger on the surface of the cheese (Figure 9), both enhancing his vision with a haptic check of the surface and displaying it for the audience. Only afterward does he utter the descriptor, which is not just "piane"/"plane" but is preceded by a long stretched "e :.:.:" sound (lasting $1.7 \mathrm{~s}$ ). This sound exhibits the elaboration, search, and

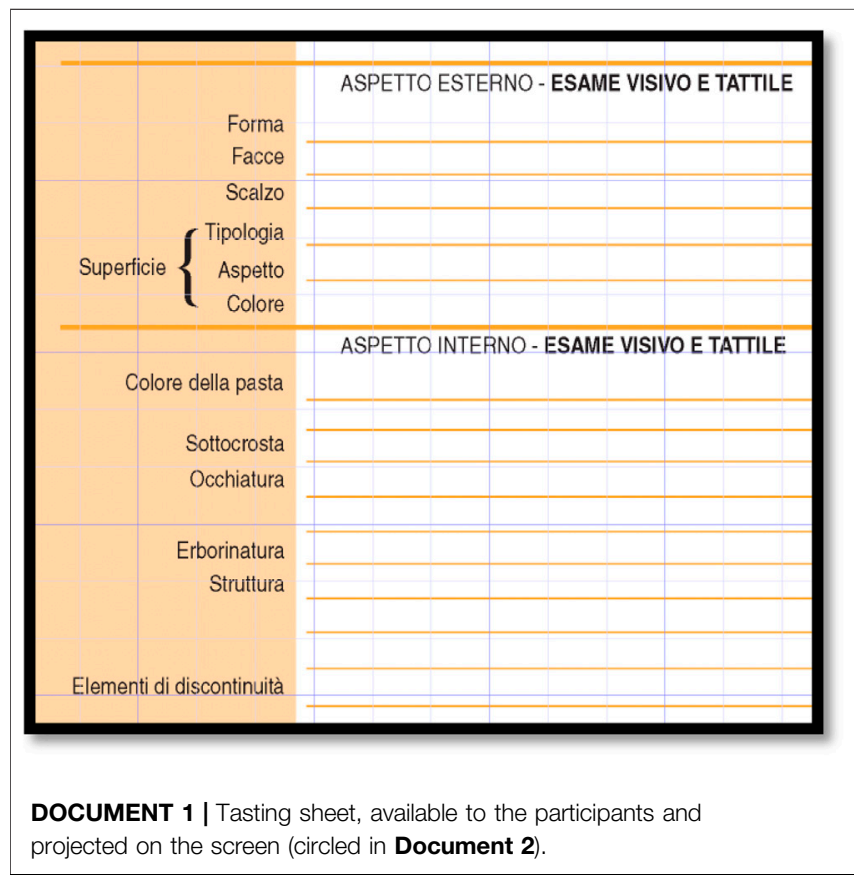

selection of the adequate descriptor, which, when found, is uttered by again touching the surface (3).

In the transition to the next category (4), the expert gazes at his computer (Figure 10), then looks at the cheese and finally raises it, still looking at it, projecting to address the audience (Figure 11). The category "scalzo"/"side" is produced with falling intonation, self-repaired, followed by the descriptor "leggermente convesso"/"slightly convex" (5). In this 


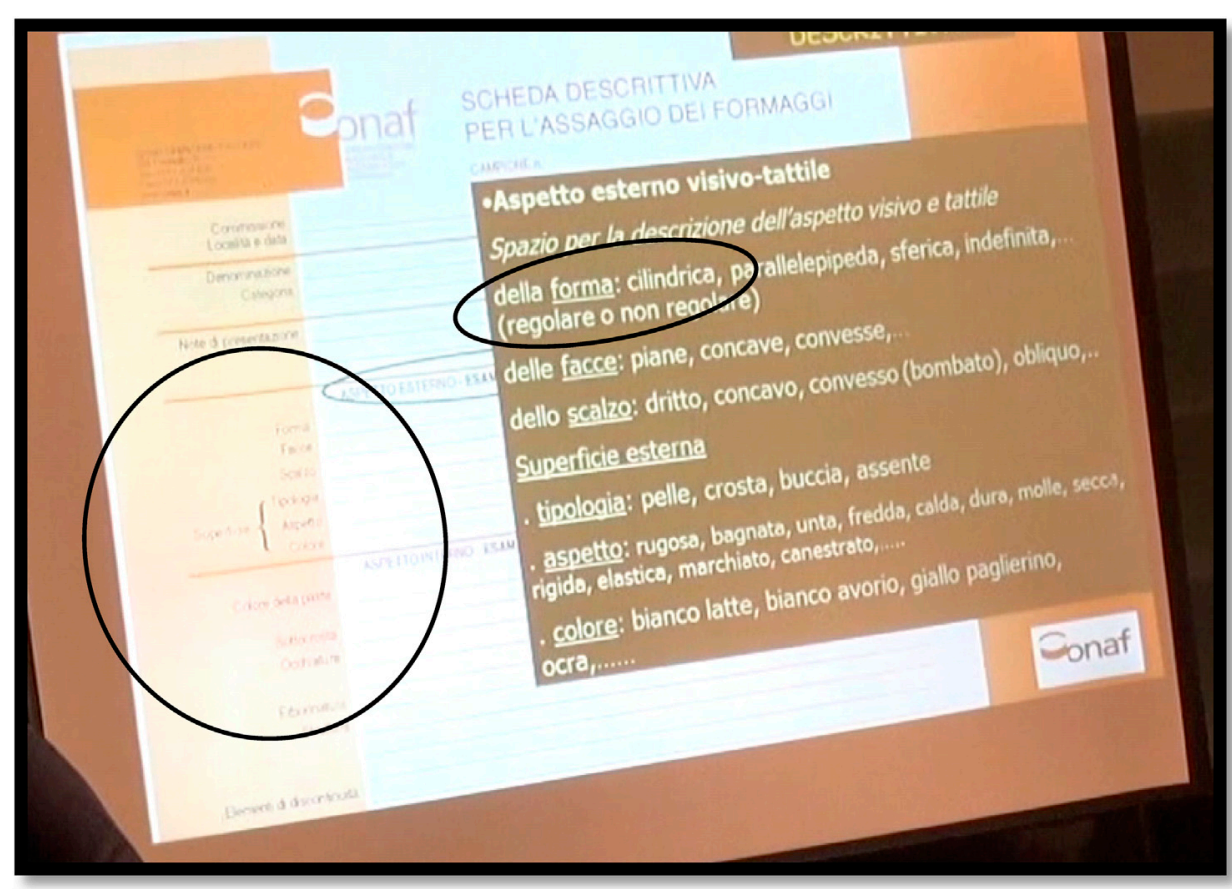

DOCUMENT 2 | Slide: projected list of selected descriptors (in black: the descriptors mentioned are circled) superposed to the tasting sheet (on the left, cf. Document 1).

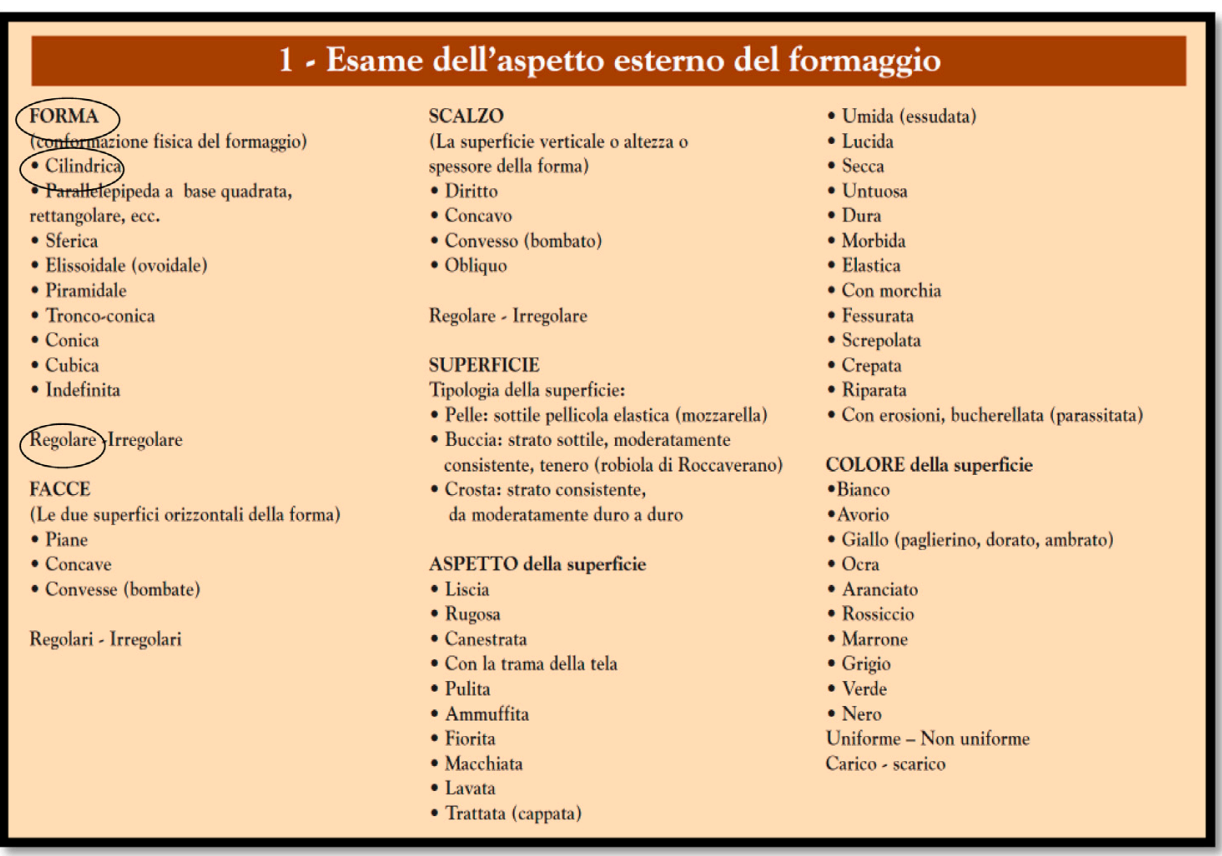

DOCUMENT 3 | Terminology sheet: list of descriptors available to the participants; the descriptors mentioned in Extract 3 are circled.

case, the expert shifts their gaze to the computer on the last syllables of the descriptor (5, Figure 12), projecting the next category ("crosta"/"rind" 7), which is described while exhibiting its visual and haptic exploration
(Figure 13). Touch co-occurs with the descriptor "elastica"/"elastic" (7), providing for its evidence and authority. The descriptor "sottile"/ "thin" (7) is produced while looking at the cheese, and an additional 


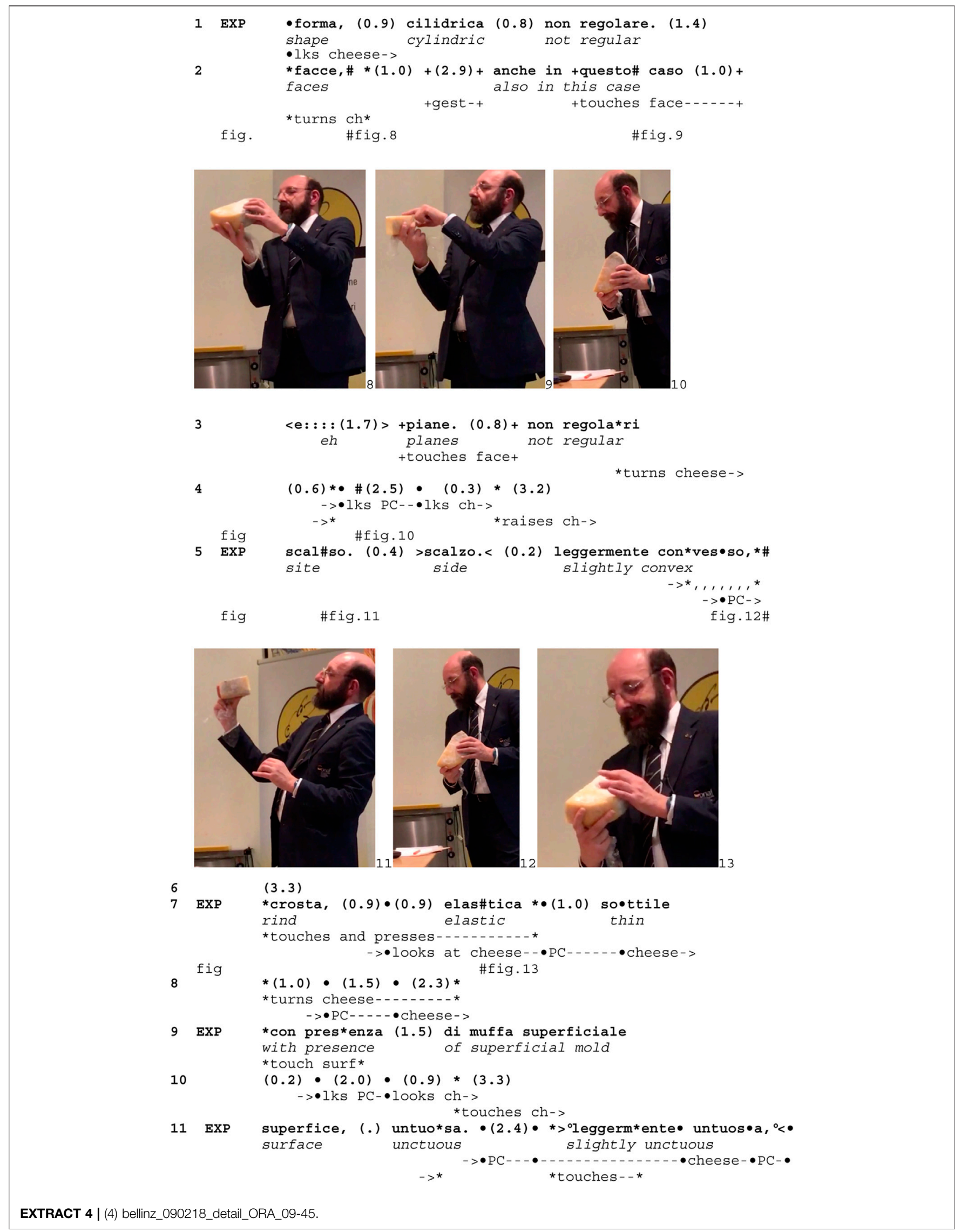


specification regarding the mold (9) is exhibited as the result of a detailed examination of different sides of the object manipulated during the long silence (8) preceding it. The gaze alternates between the cheese and the computer, the latter projecting the next item to be described (e.g., in 10). Again, "superficie"/"surface" is preceded by looking at and touching the cheese, and the descriptor "untuosa"/"unctuous" (11) is repaired into "> leggermente untuosa, ${ }^{\circ}<$ "/ slightly unctuous" (11) when touching it again, thus exhibiting a refinement of the description.

The fragment in its entirety shows the systematicity of the embodied and multisensorial practices producing the normed description of the cheese in the tasting session in a way that both addresses the standards to be used and the specificities of the object. The multimodal formatting of $\mathrm{N}+$ (pause)+Adj exhibits all this.

This format is recipient-designed: the audience is considered in the gaze shifts toward them, the showing practices adopted by the expert, and, as in Extract 2, the request for confirmation. The audience's responses are observable in different ways, as discussed in the next extracts. The participants engage in multiple activities while listening to the expert: they alternatively look at the sample shown or at the screen, and they take notes. In Extract 5, we focus on the way the description of the "occhiatura"/"eyes" (meaning the little or bigger holes in the cheese) is produced and received by one participant, Paolo, who is sitting on the first row in front of the expert (Figure 17B).

As previously highlighted, the expert silently gazes at the screen (Figure 14), then at the cheese (Figure 15), and finally at the audience (Figure 16) to whom the cheese is shown (1). Only then does he verbally mention the category and its first description (2). Further specifications are introduced with a series of gestures showing more specifically where the irregular "eyes" are distributed in the paste (3, Figure 17). After "piccola"/"small," Paolo looks up at the expert/cheese (Figure 17B), and after "grande"/ "big," he engages again in writing. What he writes (Document 4) corresponds exactly to what the expert said. In this way, the participants respond to the description of the expert by treating it as an instruction to look and see the details pointed at, and they write it down not as the mere product of a dictation but as the result of an intersubjectively shared perception and formulation.

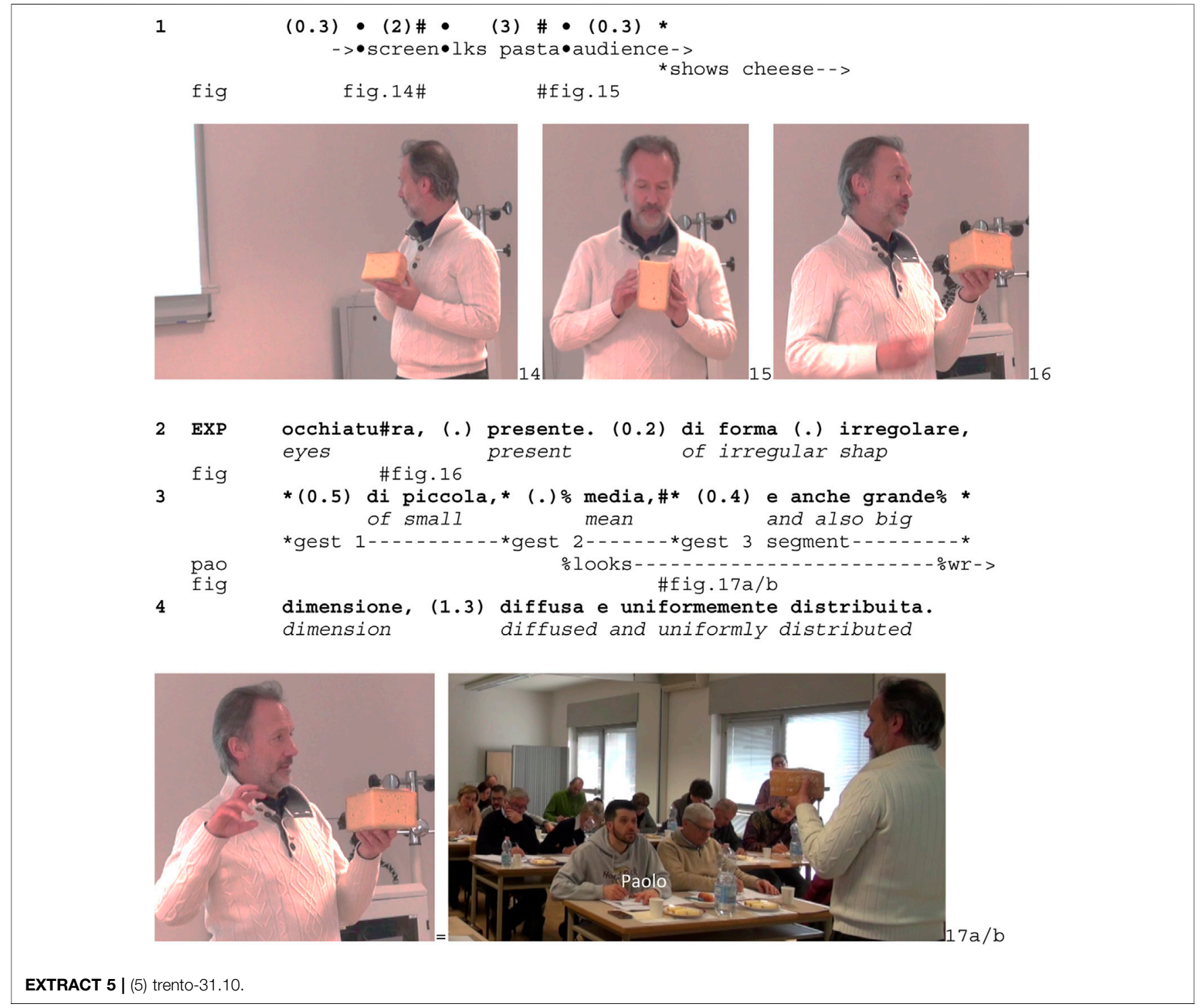




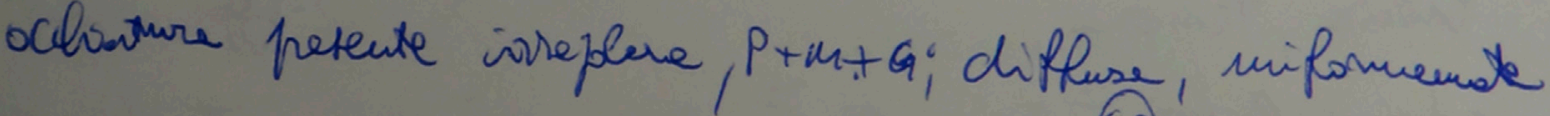 Bixtroulte.}

occhiatura presente irregolare, $\mathrm{P}+\mathrm{M}+\mathrm{G}$; diffusa, uniformemente distribuita eyes present irregular, $S+M+B$; diffuse uniformly distributed

DOCUMENT 4 | Notes taken by Paolo.

Another form of participant response is their production of some descriptors after the expert has introduced the item to describe $(\mathrm{N})$, often after glancing at the computer, and has exhibited the relevant aspect of the sample (Adj) to be looked at by the audience (Extract 6).

In this case, the category is produced while showing the cheese to the audience, with a rising intonation (1), inviting the audience to answer. Various participants produce "presente" (meaning observable, the opposite of "assente"/ "absent") (2-6) and then "irregolare" (7-9), which is confirmed among them by the expert (8). In both the cases, Paolo utters the descriptor and later on writes it (Document 5).

The recurrent multimodal gestalt consisting of glancing at the computer before uttering the $\mathrm{N}$, which corresponds to the category to be described, and in looking and showing the

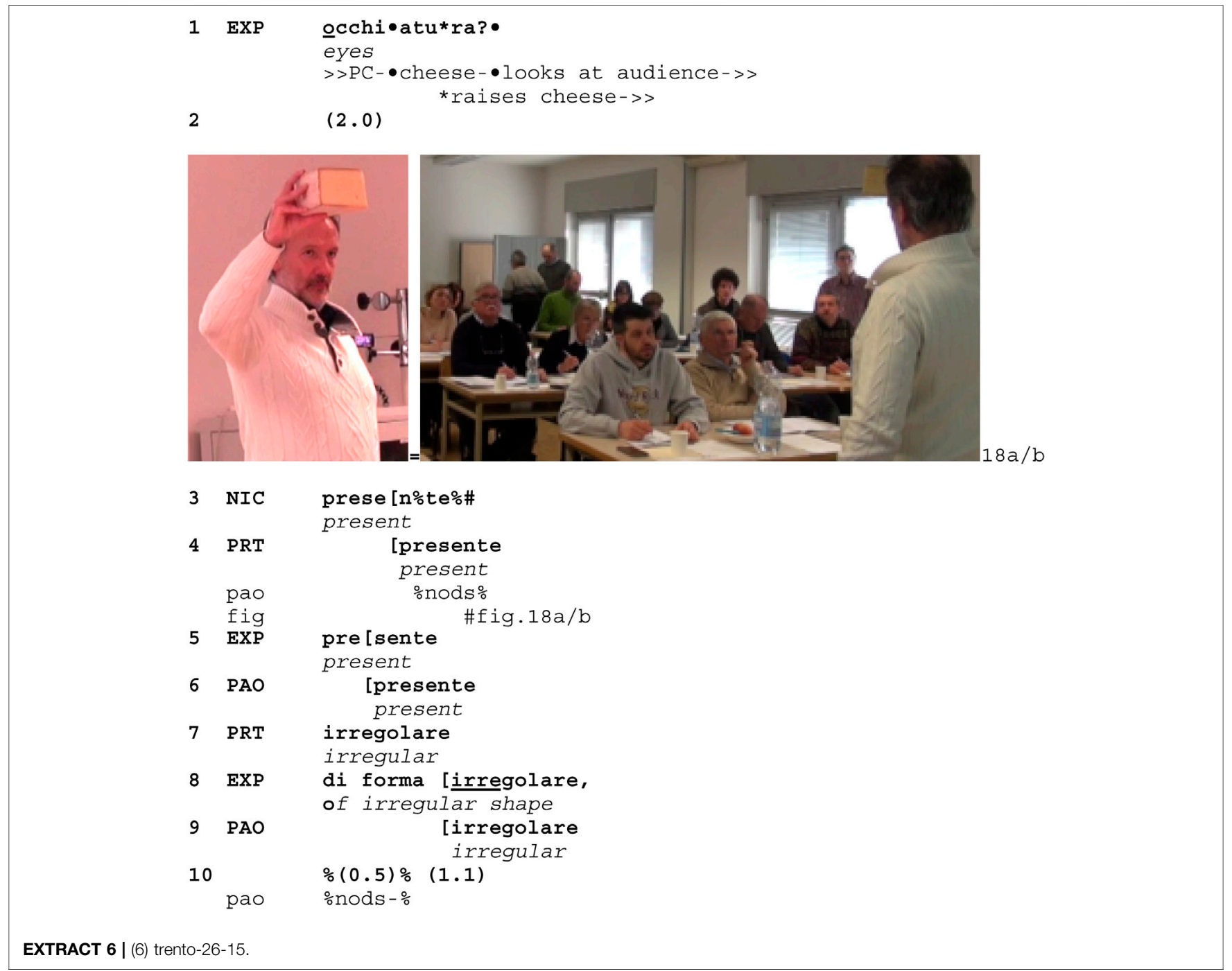




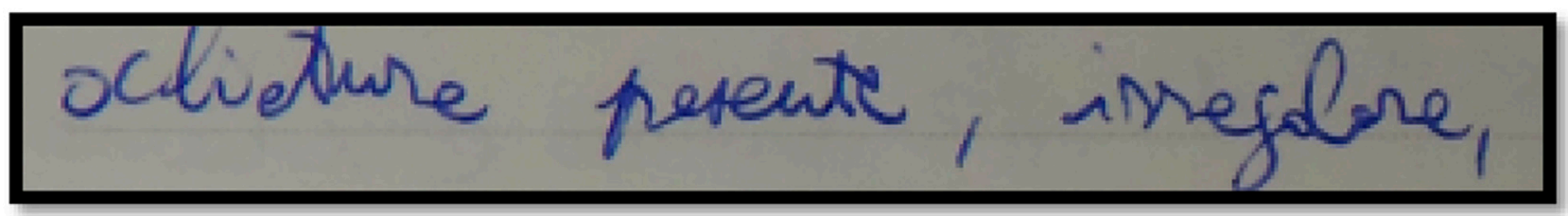

"occhiatura presente, irregolare"

eyes present, irregular

DOCUMENT 5 | Note written by Paolo a bit later.

cheese for the production of its descriptor(s) (Adj), grounds not only the methodic formatting of descriptions; it constitutes more radically a methodic organization of the global tasting procedure itself, which is generally (for all the senses considered within that procedure) structured not only by associating standard categories and their possible descriptors but also by following a normative order in which these categories are arranged on the tasting sheet. Thus, this recurrent gestalt is not only a repetitive pattern but rather a method that the expert uses and that he socializes the participants in using. Its emergent routinized character is observable not only in the responses of the participants when the $\mathrm{N}$ is announced in a question addressed to them (Extract 6,1 ) but also in them collaboratively or anticipatedly producing the descriptors (as well as the category itself, not shown here) in Extract 7.

The expert looks at his computer and utters the next category (1) while inspecting the cheese. Here "colore,"/"color" projects a continuation in the form of a descriptor (but without addressing any question to the participants [in contrast to Extract 6, 1], as shown by the continuative [vs. rising] intonation and the absence [vs. presence] of gaze toward the participants (cf. Stivers and Rossano 2010). The following pause (2) is used by the expert for inspecting the cheese prior to his description. Some participants

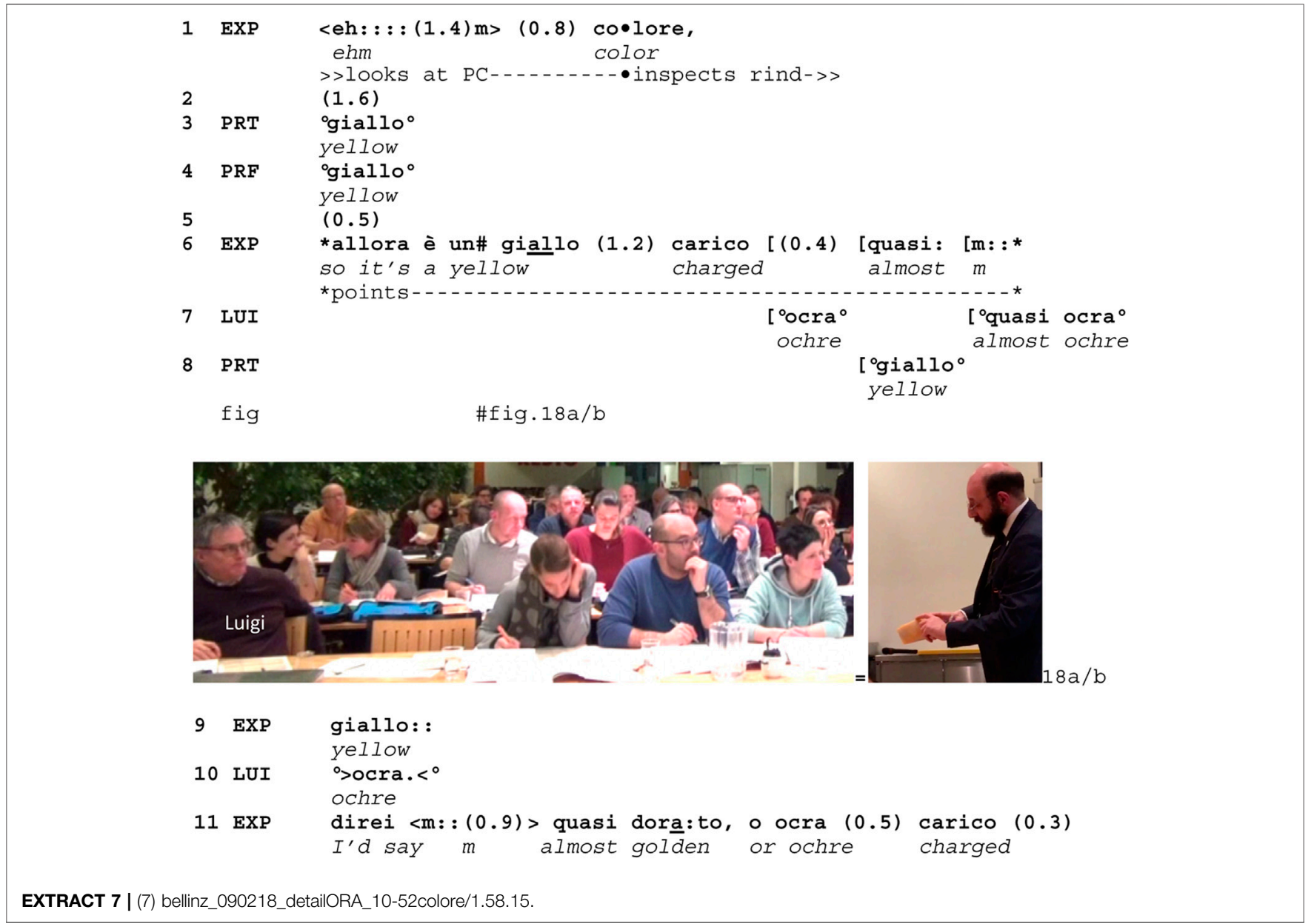


anticipate it (3-4), collaboratively proffering a term of color. The expert here both confirms and corrects (6): in this case, he uses a clause (and not the simplest format $\mathrm{N}+\mathrm{Adj}$ ), in which the initial "giallo"/"yellow" is modified in a way that is anticipated and suggested by one participant (Luigi, 7, circled in Figure 18). By showing his continuous engagement with the cheese (Figure 18B), the expert displays that the issue is not settled and various options are available. By repeating "giallo::" (9) in a way that projects a modifier of that color, the expert shows that he is moving along a gradation of yellows, whereas the participant suggesting "ocra"/"ochre" $(7,10)$ points at the next color in the ordered terminological list (Document 6). This structuring of the lexicon of colors along a continuum is already hinted at by the use of "quasi"/"almost" $(6,7,11)$, which points at the possible relevance of the next category ("ocra"/"ochre" instead of "giallo"/“yellow").

In this case, there is a hesitation concerning the descriptor and a possible disagreement among the participants: the expert uses a clause rather than the simplest $\mathrm{N}+$ Adj format. This shows that the choice of the syntactic format relates to the more or less straightforward character of the description, as we shall see in the next sections, which focus on possible expansions and complexifications of this minimal standard format.

\section{EXPANSIONS OF THE SIMPLEST FORMAT}

An expanded version of the simplest format analyzed in the previous section can be observed. In these cases, the simplest format is preserved and used to introduce a first descriptor; nonetheless, the next descriptors are presented in a less takenfor-granted way and as depending on what can be said and seen. This expanded format can be prosodically projected at the end of the N + Adj (Extracts 8-11) or can be added after a renewed examination of the object (Extract 12). The expanded format contains explicit references to the activities-sensorial practices, verbal practices-that make the procedure possible

\section{COLORE della superficie}

-Bianco

- Avorio

- Giallo (paglierino, dorato, ambrato)

- Ocra

- Aranciato

- Rossiccio

- Marrone

DOCUMENT 6 | Extract from the terminology sheet. and grant its evidentiality. It is also characterized by hedges, hesitations, and sound stretches, displaying that the description is possibly difficult.

Here are four cases (Extracts 8-11) that present some recurrent systematic features:

Theexpert introduces the category (Extract 8, 1: "occhiatura"/"eyes"; Extract 9, 2: "forma"/"shape"; Extract 10, 1: "sottocrosta" "undercrust"; Extract 11, 1: "scalzo"/ "side") and a first descriptor (Extract 8, 2: "piccola, media," "small medium"; Extract 9, 2: “cilindrica"/ "cylindric"; Extract 10, 1: "presente"/"present"; Extract 11, 1: "diritto"/"straight"). While at this point the description could be considered complete, in these cases, it is expanded. Expansions refer to a possible saying (with the verb "dire"/ "say" preceded by a modal verb in the 1 st person singular or plural, "possiamo dire"/“(we) can say," Extracts 8, 11, "posso dire"/(I) can say," Extract 9, 4). These ways of saying are related to ways of looking ("se noi guardiamo"/"if we look," Extract 8, 14; "guardandola"/"looking" Extract 9, 4; "perchè si vede molto bene"/“cause one sees (it) very well” Extract 10, 3; "perchè presenta [...] molto evidenti”/“cause (it) presents [...] very evident" Extracts 11, 2), which are a condition, a circumstance, or a reason that enables the saying. Thus, the expansions formulate very explicitly the evidentiality that grounds and conditions the description, formulating the possibility of saying as depending on practices of looking and seeing, which are also embodied by gestures and showing movements. Moreover, these expansions do not just mention the practice of seeing but are instructions to see addressed to the audience, whose response is here (contrary to the previous environment, with the exception of Extract 2) explicitly mobilized (Extracts 9, 5: “no?"/"no," “occhei?”/ "right"; Extract 10, 3, Extract 11, 4: "vedete?"/ "see"-requesting confirmation of what they see) and immediately provided in all the cases (in Extracts 8 and 11 by Paolo nodding and in all extracts by the response tokens of some participants).

The expansion of the initial description treats the recognition and assessment of the features as not straightforward-as not merely corresponding to the standard (hinted at by the $\mathrm{N}+\mathrm{Adj}$ format) and even locally departing from it, as revealed by deictic expressions such as "in this case" (Extracts 4, 9 and 2, 10) or "here"/qui" (11, 1)-and as needing to be grounded in particularly attentive ways of looking and seeing, secured by the professional vision of the expert (Goodwin 1994) and enabled for the participants by instructing their vision.

This can lead to some contestation, as in the following case: the expert introduces a description in the $\mathrm{N}+$ Adj format (1), prosodically complete, but after a moment of tactile inspection (3) adds a possible optional specification, "spigolo vivo"/"sharp edge" (4) (Extract 12a).

In the expansion, the expert introduces "spigolo vivo"/ "sharp edge" (4), using the modal verb "want" in the gerund mode, "volendo," followed by a verbum dicendi "possiamo (1.1) eh indicare" (4). He shows the edge with his fingers (5) and further expands the reasons for mentioning this feature, 


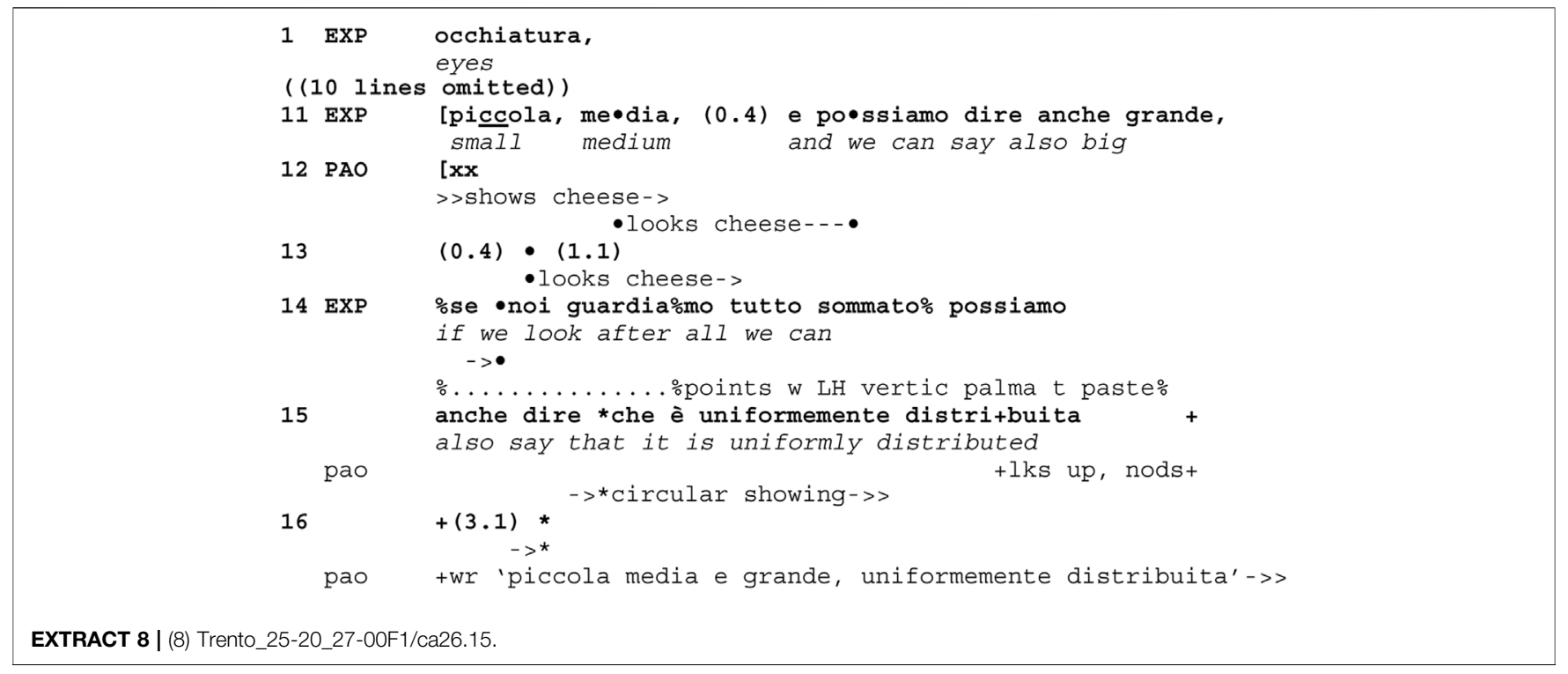

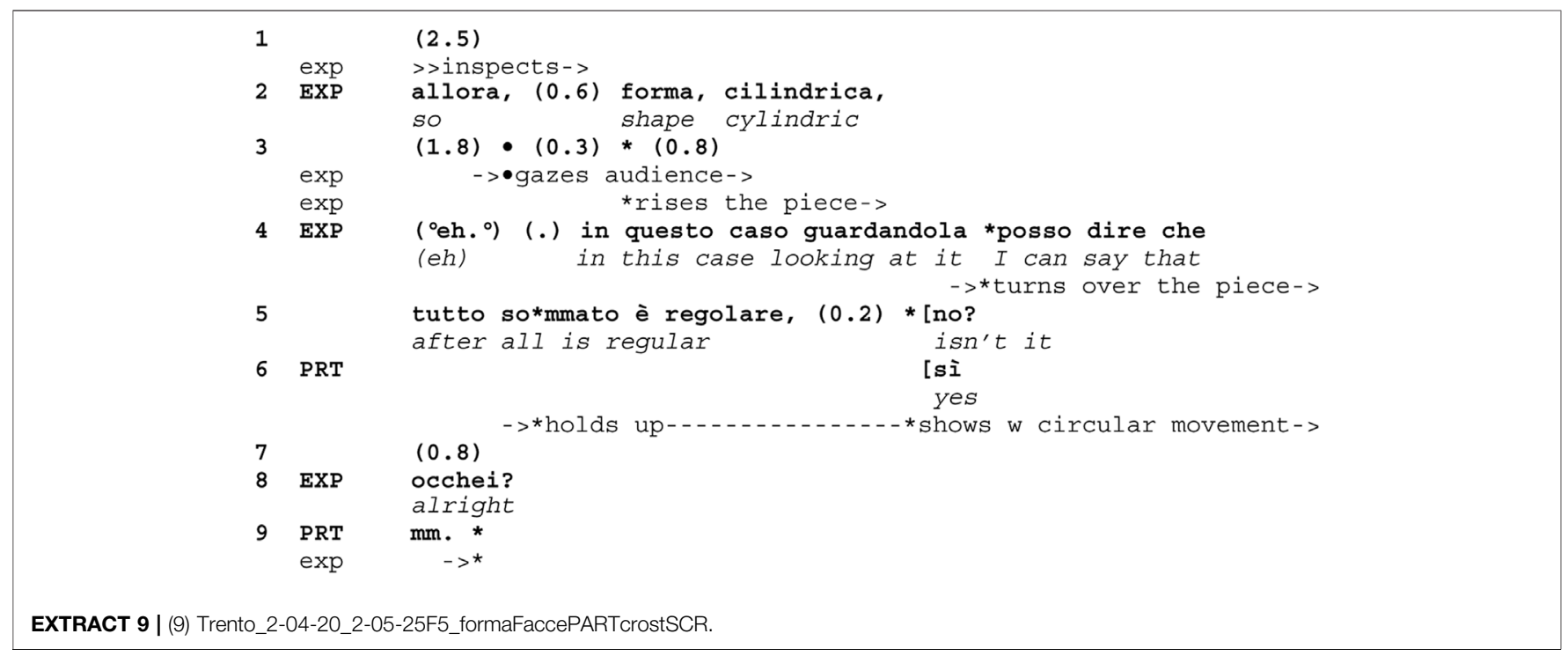

after a repair initiated by a participant (6), still showing the piece (Figure 19A) and highlighting the straight form of the "scalzo"/"side." Among the participants, Luciano (circled in Figure 19B) looks several times at the cheese, first when the side is mentioned (2), then when the edge is introduced (4). Each time he also looks down at his notes and writes. When the expert elaborates on the relevance of this feature for some cheeses (10), Luciano looks up again. Now his facial expression changes, and he frowns in a continuous way, while still looking.

This facial expression is relevant for what happens approximately $4 \mathrm{~min}$ later. The expert has explained other features also concerning the external aspect of the cheese. At some point, Luciano self-selects, coming back to the form of the side and negating the previously described feature "diritto"/ "straight" (Extract 12b).
Luciano's objection is related (and relativized with respect) to his visual perspective ("guardando da qui"/"looking from here" 1). Luciano's negative increment (4) orients to the absence of a response on the part of the expert, who then responds positively (6) while walking toward him, showing the sample (Figure 20). Luciano proposes an alternative descriptor ("obliquo"/"oblique" 8) in a negative interrogative form, orienting to a possible rejection by the expert, who indeed disagrees (10) despite a minimal concession (with "appena appena"/"barely barely" 10). Luciano aligns with the latter, proposing a modifier ("leggermente" " "slightly" 12), which is repeated by the expert (13) as he walks back to his initial lecturing position. Another participant, Lara, sitting beside Luciano, seems to agree with him in a hyperbolic way (14, but the transcript is uncertain). The expert moves from a debate with 


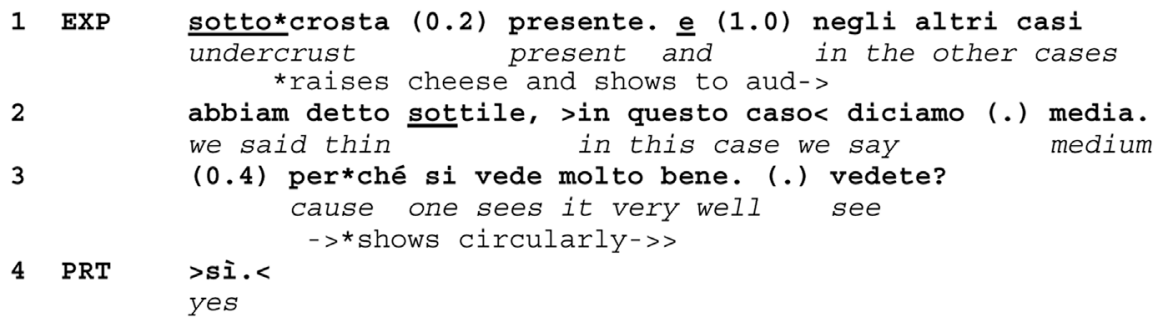

EXTRACT 10 | (10) Trento_1.57.35_sottocrosta.

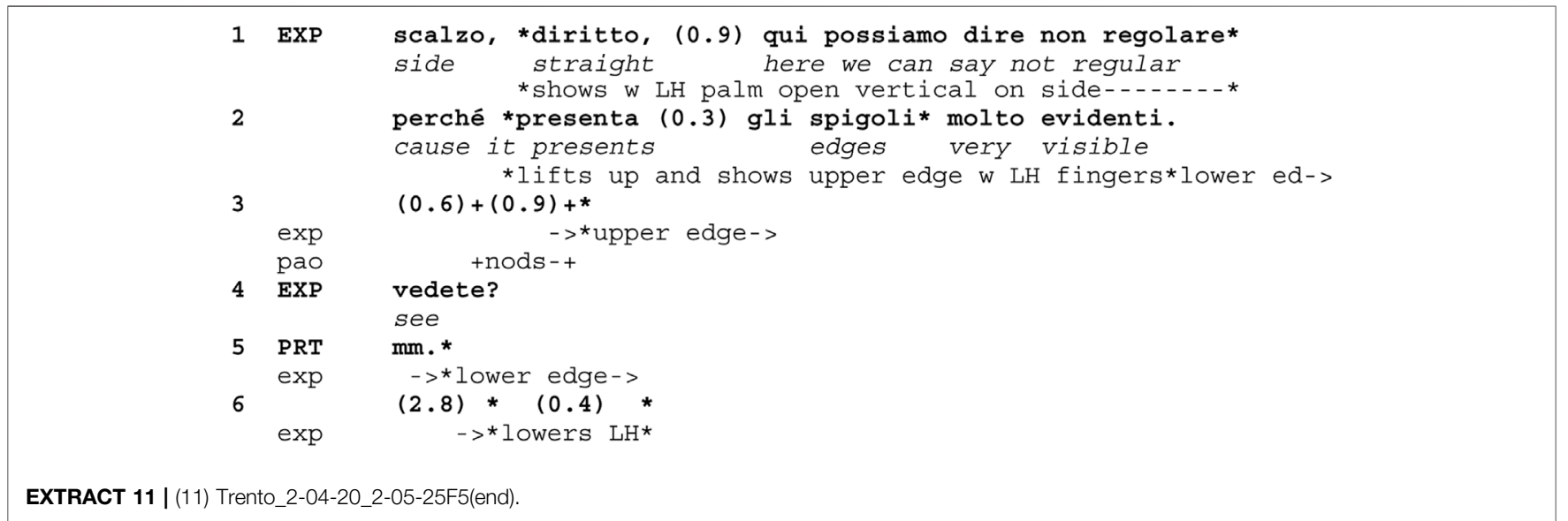

Luciano to a general address to all the participants (15-19) and recognizes the relevance of his alternative description. He does so, however, by referring to those holding that position as "assolutamente pedanti"/“absolutely pedant" (16) and modifies the description "obliquo"/"oblique" with a superlative form ("leggerissimamente"/"very slightly" 19) of the adverb used by Luciano ("leggermente"/"slightly"12-13), which he had previously conceded. This is highlighted by Lara (20).

This case shows how a locally expanded description can be legitimately contested by the participants. The use of formats other than the straightforward normative $\mathrm{N}+$ Adj produces the hedged character of the description. This in turn is vulnerable to contestation based on the autonomous visual access of the participants to the object exhibited to them. Moreover, Luciano's counterproposal is also made possible by the available list of descriptors (Document 7), to which the participants have access, in which "diritto"/"straight" is the first option, "convesso"/ "convex" has been excluded by the expert, and "obliquo"/"oblique" is the last one. Thus, the shared visual evidence, combined with available lexical options legitimated by the official terminology, generates possible contestation, thereby displaying the increasing autonomy of the participants.

Further expansions of the initial $\mathrm{N}+$ Adj format include possible problematizations of the choice of the Adj on the basis of variable conditions of looking and seeing as well as available options. Expansions introduce an instructional dimension (explicit in the if/then clause "se guardiamo tutto sommato possiamo anche dire che"/"if we look after all, we can also say that" Extracts 8, 14, 15, see De Stefani, this issue) that opens up possible doubts, discussions, and contestation. Further elaborations of the syntactical formats highlight the conditional, specific, relativized status of the description.

\section{THE USE OF COPULAR CLAUSES}

The format $\mathrm{N}+$ Adj also contrasts with the copular clausal format "the $\mathrm{N}$ is Adj." Whereas the former is used in contexts in which the standard descriptors are straightforwardly usable, the latter rather addresses the nonfittedness of the descriptor regarding specific features of the object. The article preceding the noun expressing the category (vs. the category as an isolated $\mathrm{N}$ ) projects some elaboration of its description. In other words, the $\mathrm{N}+$ Adj format is functional in clear-cut cases in which the adjective fully applies to the described object. By contrast, in cases in which the description is more difficult, either $\mathrm{N}+$ Adj is expanded or the description is formatted from the beginning as a clause. The expanded format is more emergent; the choice of the clausal format supposes an early projectability of the trouble.

In the next extract (Extract 13), the expert has shown a very irregular piece of cheese, recognized as such by all the 


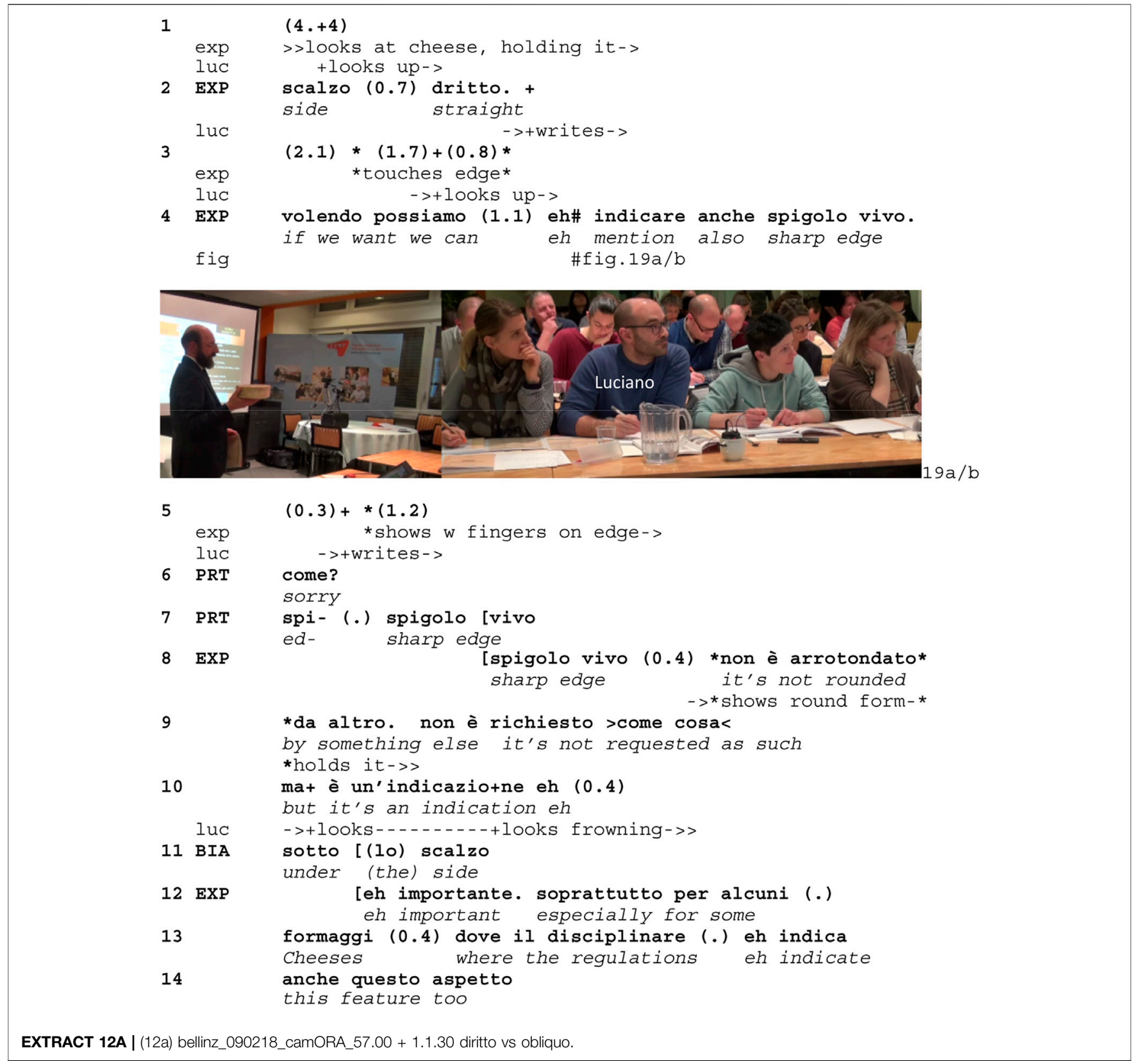

participants. He then initiates a more analytical development of this specificity.

The anomalies of the cheese have been looked at and seen by the participants. The next category ("scalzo"/"side" 3) is introduced by a preface alluding to these anomalies, inviting the adoption of an analytical eye. This is not only introduced by a clause (3) but is also exhibited by the fact that just after the copula, the expert produces the adjective "diritto"/"straight" in a very peculiar way. First, there is an audible pause of $0.6 \mathrm{~s}$ after the verb, during which the expert raises the cheese (Figures 21, 22) and makes it visually available for the audience. When he begins to utter the adjective, he shifts his gaze from the audience to the cheese, looking at it (Figure 23). In the middle of the adjective, he pauses, still looking at it, leaning his head a bit to the left
(Figure 24) before resuming his talk and completing the adjective with a head toss (Figure 25). This way of pausing in the middle of the descriptor exhibits in an audible (through silence) and visible way his public inspection, preceding and legitimizing the completion of the descriptor. This is oriented by Paolo, in front of him, who, in the middle of the pause, shakes his head and produces a disaligning " $\mathrm{mm}$." (4), and adds another head shake on the last syllable of "diri (0.6)tto." So, the speaker and at least one member of the audience exhibit their orientation to the difficulty encountered in using that descriptor. Then the expert continues with a list of features, which is completed by a request for confirmation (8).

The next extract (Extract 14) provides another case in which the contrast between the clause and the nonclausal $\mathrm{N}+$ Adj format is 


\section{LUC}

2 $(0.5)$

4 LUC 0 no?*

or not

->*stops, raises cheese to show->

5

$\exp$

$6 \operatorname{EXP}$

7

$\exp$

fig

sorry can I ask something

lo sca*lzo non mi sembra diritto. *walks twd LUC----->

(2.9) \%(0.4)

\%finger along side->

direi di sì.

I would say yes

$(0.6) \cdot(0.4) \#$

-looks at LUC->

\#fig. 20 scusi posso chiedere qualco+sa. guardan+do+ da qui però $+\ldots$ points---+, ,

the side does not seem straight to me

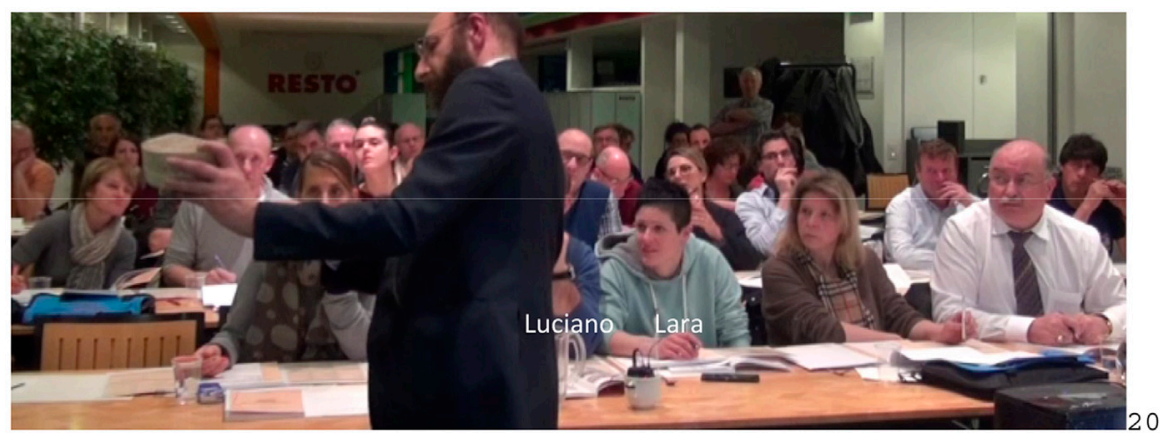

8 LUC non è obliquo?•

isn't it oblique

$\exp$

9

$(0.6)$

$->\cdot l o o k s$ at ch, holding it->

$10 \operatorname{Exp} n: 0(0.4)$ no\% qui appena\% appena ma $n$ :

no no here barely barely but $n$ :

->\%finger on side\%

11 direi che \%non $(0.5)$ non $(0.9)$ non andrei

I would say that I w'd'nt w'd'nt w'd'nt go

12 LUC ${ }^{\circ}$ legger [mente oturns cheese->

$13 \operatorname{ExP}$

slightly

[leggermente s- \%*>allora.< eh slightly $s-$

$->\%$

->*walks back to presenting position->>

14 LAR hh .h ('sembra una piramide ${ }^{\circ}$ ) .hh

(looks like a pyramid)

$15 \operatorname{ExP}$ non è peregrina $(0.7)$ questa: it's not peregrine this eh we notice that on this side the side is 


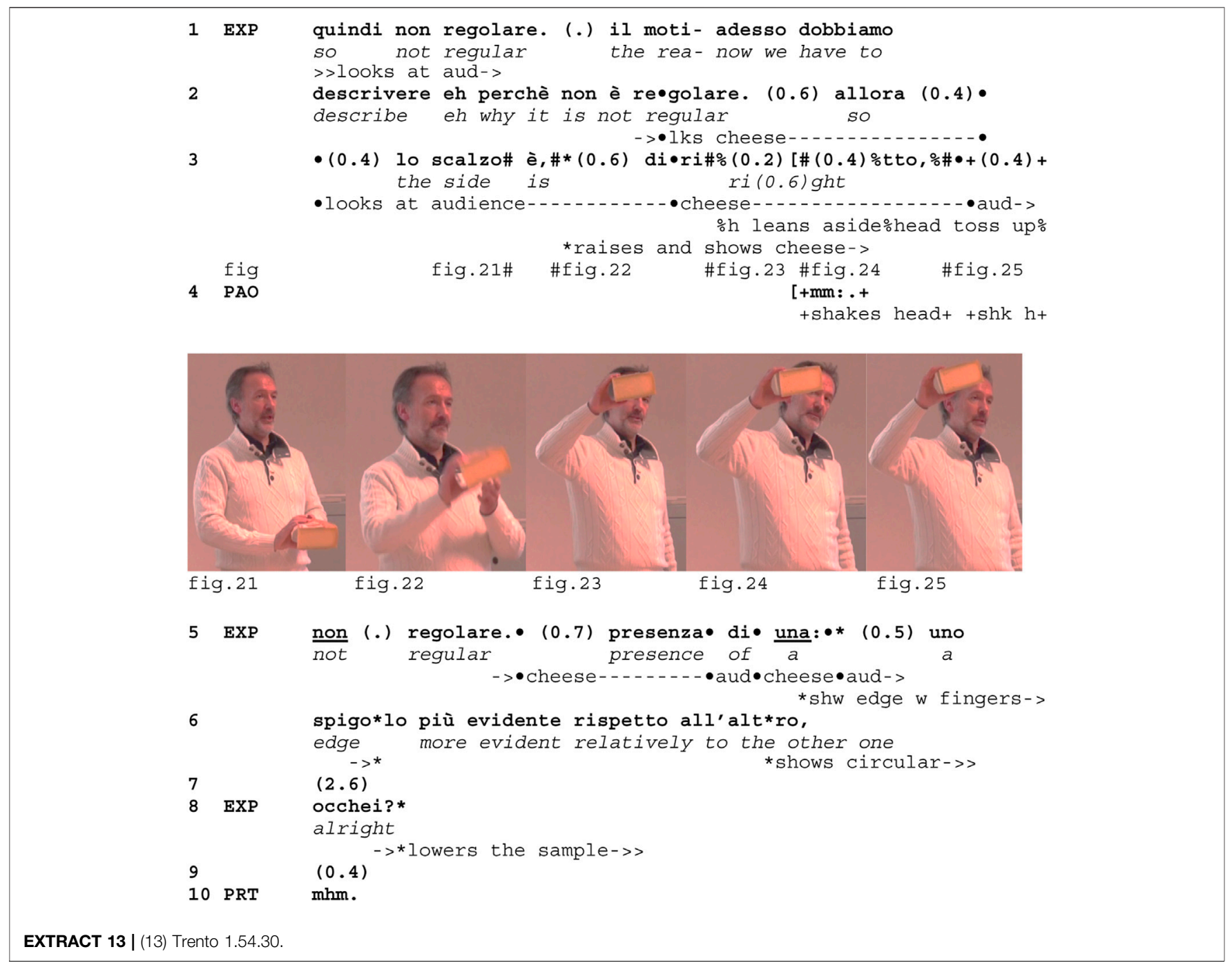

observable. The expert is inspecting and describing an atypical cheese which comes from Nepal. He notices that the surface is irregular and makes some hypotheses about its causes. The description starts with Art $+\mathrm{N}$ projecting a copula and a descriptor. It is noticeable that, even in this case, there is a continuing intonation on the end of the noun, a pause (see Extract 13,3), and a copula followed by a continuing intonation also (see Extract 13,3) projecting the Adj. In this case, an expansion with a relative clause is introduced by the verb "have" ("abbiamo" 1 ).

The expert manipulates the piece, inspecting it while speaking. Syntactically there are several restarts, indexing the difficulty of describing it. The expert negates the feature of regularity (2-3), with a participant expressing some incipient dissent (4), and proposes a hypothesis for the visible and haptic irregularities, which, despite their contingent nature (problems during transport), are attributed to the sample. The reasoning for the vicissitudes suffered by the cheese is based on its careful
SCALZO

(La superficie verticale o altezza o spessore della forma)

- Diritto

- Concavo

- Convesso (bombato)

- Obliquo

DOCUMENT 7 | Extract from the terminology sheet). 


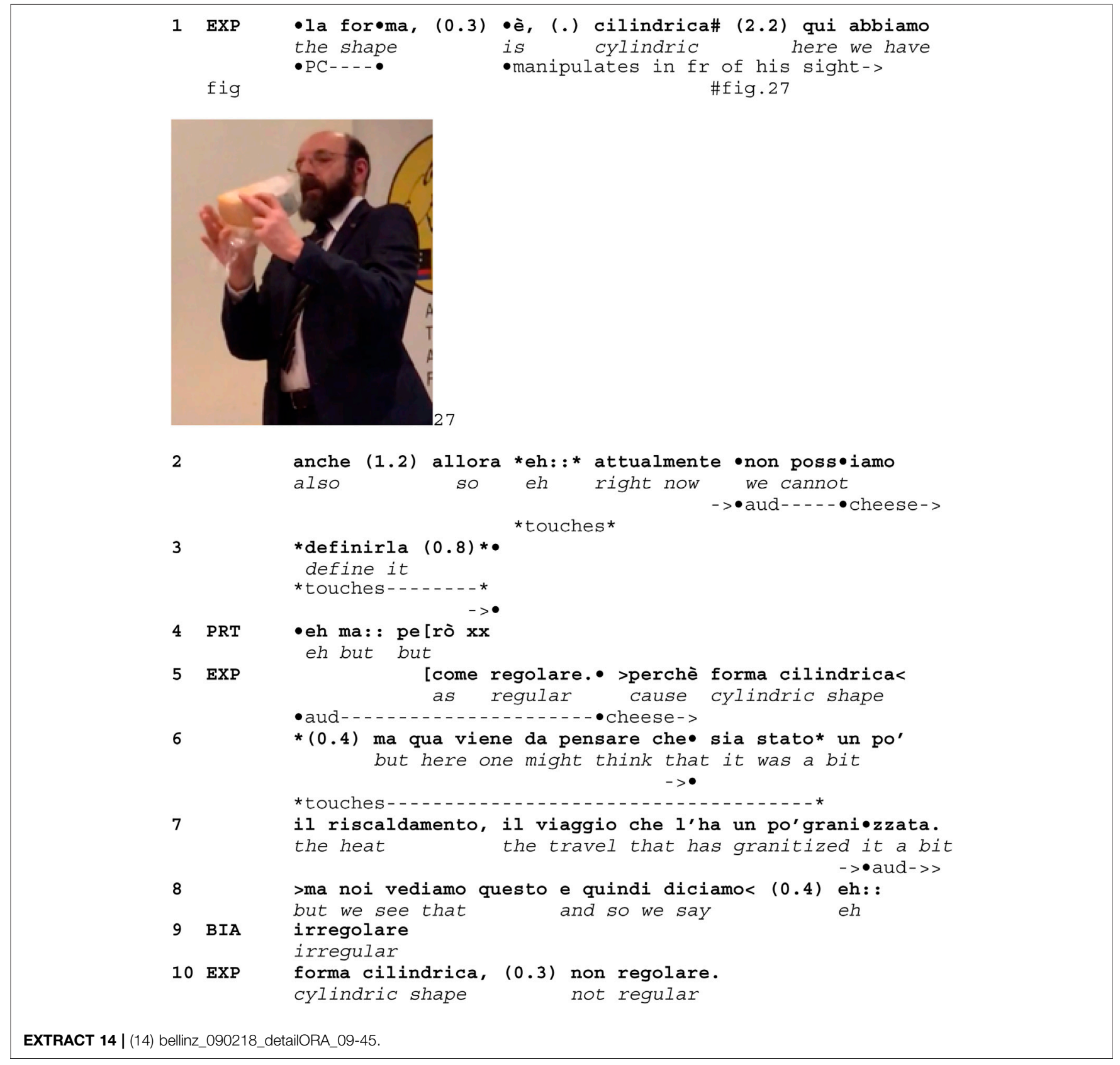

examination and deduced from its observable characteristics. The conclusion is introduced by a verbum dicendi (8), which projects the final description and which enables a participant, Biagio, to offer a collaborative completion (9). The expert, however, does not acknowledge it but produces a standard $\mathrm{N}+$ Adj description (10) (the expert disaligns with the proposal of the participant, "irregolare" 9, by producing instead "non regolare" 10-both variants are present in the normative documents, the former on the terminology list, the latter on the expert's slide). The disalignment enhances the asymmetry between the participants.

So, this extract begins with a clause in a copular format and is finally completed by redoing the description, this time in a minimal $\mathrm{N}+$ Adj format. This shows that once the descriptive problem is solved, the object is described in a standard way: its features have been normalized in the discussion.

\section{DEVELOPMENTS WITHIN COMPLEX SENTENCES}

While the simplest format $\mathrm{N}+$ Adj expresses the standard pairing between a category and a descriptor, more articulated forms of syntax make possible a more malleable description and possibly combine different aspects, which are treated separately in the available lists. These formats are often introduced by the verb "abbiamo"/"we have," referring to what is made available to the examiners rather than to a 
quality of the object (expressed with the copula). Thus, more articulated forms of syntax enable the expert to adhere to the specificities of the object as he perceives them, especially when they are not clear-cut or are difficult to capture with a unique descriptor rather than following the normative hierarchies and orders of the lists. This can lead to contestation or puzzlement among the audience, especially when they orient to the normative model.

Extract 15 shows such a description, which nonetheless continues to rely on the official terminology.

The first category ("crosta"/"rind") is introduced by the verb "noi abbiamo"/"we have" (1) and described with a series of adjectives ("elastica" "elastic" 2, "sottile"/"thin" 4, "rugosa"/ "wrinkled" 6, "marchiata"/"branded" 9), which are all mentioned on the slide (Document 8) but one: the expert's description also includes the thickness of the rind, which is a criterion belonging to the next step of the procedure, the examination of the paste. Despite the slide not mentioning "trama della tela"/"texture of the cloth" (6), this characteristic is mentioned in the more complete list accessible to the participants. So, the expert does not follow the slide blindly; quite the opposite, he rather follows the structure of the object he holds in his hands (and topicalizes his own visual perception, 3 ). However, the relevance of the available (and projected) list is observable in the final question asked by a participant (12) pointing at the category color as still missing (it is the last in the list projected on the screen, Document 8).

Each feature is examined, visually or haptically, and shown (by pointing). These movements precede the uttering of the descriptor and ground them on direct sensorial access. For instance, "abbastanza elastica"/"relatively elastic" (2) is preceded by the hand touching and pressing the rind, haptically exploring it (Figure 26); "abbastanza sottile"/“fairly thin" (4) is preceded by looking and pointing at it (Figure 27); "leggerm-rugo:sa"/"slightly wrinkled" (5-6) is preceded by rubbing the rind with the fingers (Figure 28). In all the cases, the Adj is modified as a gradable quality. The difficulty of evaluating the graduality of the descriptor is explicitly hinted at by the head toss (4) co-occurring with "abbastanza sottile" (4). It is also hinted at by references to possibly asymmetric visual perspectives and access (7), although the detail is shown and pointed at in front of the audience (Figure 29). Moreover, this description is prefaced by a long stretched sound (3) - " ><eh::::(0.9)<m:::(0.7)>" - transcribed by indicating its length. The same happens with "leggerm-rugo:sa," preceded by < eh:(0.3) $><$ m:::::(0.9) $>$ (5), and "marchiata," preceded by "<eh::::(1.0) $><\mathrm{m}::(0.6)>$ " (9). These stretched sounds make audible the ongoing process of sensing that precedes and informs the descriptor. They are integrated into the ongoing progressivity of the description and indeed exhibit it and the conditions that make it possible.

A last extract shows another instance of a description that arranges various features in an emergent incremental multimodal turn. In this case, the free arrangement of the description in a complex elaboration provokes some puzzlement in the audience, who rather orient to the official documents and the hierarchy of the normative descriptors contained in them. The turn starts with a bare $\mathrm{N}$, followed by a pause, and then a description introduced by the verb "have" ("ha" 1 ). The bare $\mathrm{N}$ is used as a title (separated by the pause from what follows) of a discursive development to come (vs. as the beginning of a clause integrated within it). As we shall see, this format is justified by the complexity of the materiality to be described (Extract 16a).

The expert mentions the overall category "superficie"/surface" (without article) as a starting point and category that will be described. He then continues, after a significant pause, with the verb "ha"/"has," which predicates something about it: the entire description depends on this verb and on its object ("una colorazione"/“a coloring" 1) and aggregates together a series of features thanks to two prepositional phrases (initiated by "con"/ "with" 2 and "di"/"of" 4) (ha una N Adj con X di Y). This description alternates the examination of the object and the orientation to the audience, observable in the gaze shifts and also in the progressivity of the talk. The first feature of the surface's coloring is expressed by an adjective ("regola:re"/"regular" 2), which is presented as unproblematic and is recipient-designed by the gaze to the audience (a brief gaze to the cheese precedes "una colorazione" and "regola:re" while the expert turns the cheese various times and displays that this feature can be captured at a glance). By contrast, the first prepphrase beginning with "con"/"with" is characterized by long stretched vocal sounds ("m:.:.::"2, "m:.:.:"3) that precede "colorazione bianca." During the production of these sounds, the expert inspects the object not only visually but also haptically. The second prepphrase (4) is unproblematic too and specifies the cause of the color that has just been described. So, the issue here seems to concern the exact color of the rind-for which the word "colorazione"/"coloring" and not "colore"/"color" is used.

This description raises several problems among the audience, which are observable in the continuation of the extract. As we shall see, there is a double orientation of the participants toward the material features of the object-on which the previous extract focuses entirely - and the tools assisting its examination, namely the tasting sheet and the terminology lists-which are not considered by the expert during his description. As a matter of fact, the syntactical arrangement chosen by the expert in Extract 16a associates some descriptors in a way that does not correspond to their order in the terminology list he projects on the screen and which the participants have on their table. In the terminology list (Document 9), the description is structured according to three categories: surface ("superficie," coinciding with the "tipologia"/"typology" of the rind), aspect ("aspetto," which includes "ammuffita"/"moldy"), and color ("colore"/ "color," which includes "bianco"/"white," "giallo"/“yellow," "marrone"/"brown," etc., as well as its uniformity: "uniformenon uniforme"/“uniform"-"not uniform”). The expert's description in Extract 16a associates two features that are dispersed under different categories of the list: he describes the "colorazione"/"coloring" of the surface as "bianca"/"white" and mentions the "muffa"/"mold" that causes it. The former refers to the color (although "colorazione" is not "colore"), and the latter refers to the aspect (although "muffa" is not "ammuffita"): in this sense, he mixes up descriptors coming from two distinct categories in the terminology sheet, thus ignoring their normative order. He also uses expressions that are similar but not identical to the ones on the list. The complex syntax (vs. the 


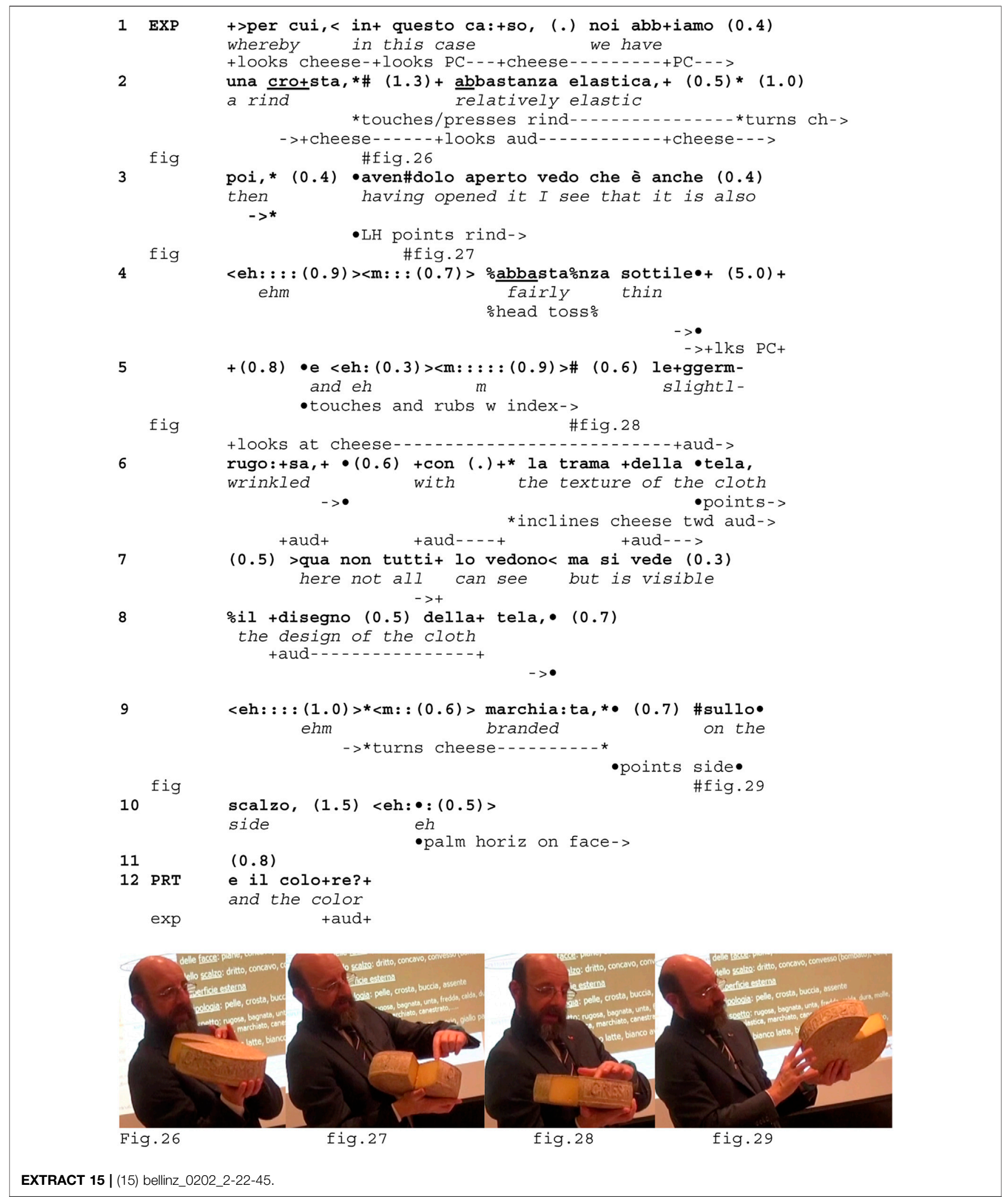




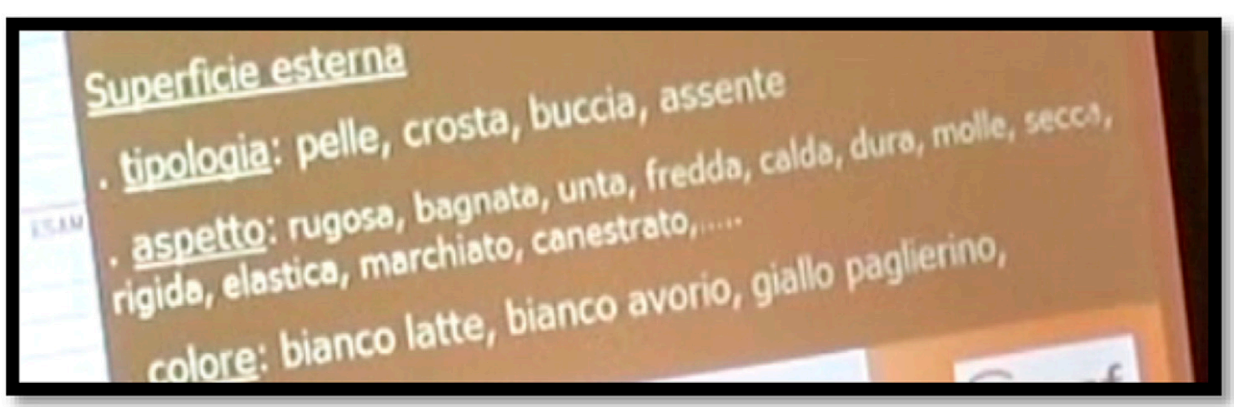

DOCUMENT 8 | Slide projected.

\section{1 - Esame dell'aspetto esterno del formaggio}

\section{SUPERFICIE}

Tipologia della superficie:

- Pelle: sottile pellicola elastica (mozzarella)

- Buccia: strato sottile, moderatamente consistente, tenero (robiola di Roccaverano)

- Crosta: strato consistente, da moderatamente duro a duro

ASPETTO della superficie

- Liscia

- Rugosa

- Canestrata

- Con la trama della tela

- Pulita

Ammuffita

- Frorita
COLORE della superficie Bianco

- Avorio

- Giallo (paglierino, dorato, ambrato)

- Ocra

- Aranciato

- Rossiccio

- Marrone

- Grigio

- Verde

- Nero

Uniforme - Non uniform

Carico - scarico

DOCUMENT 9 | Excerpts from the terminology sheet (not entirely reproduced).

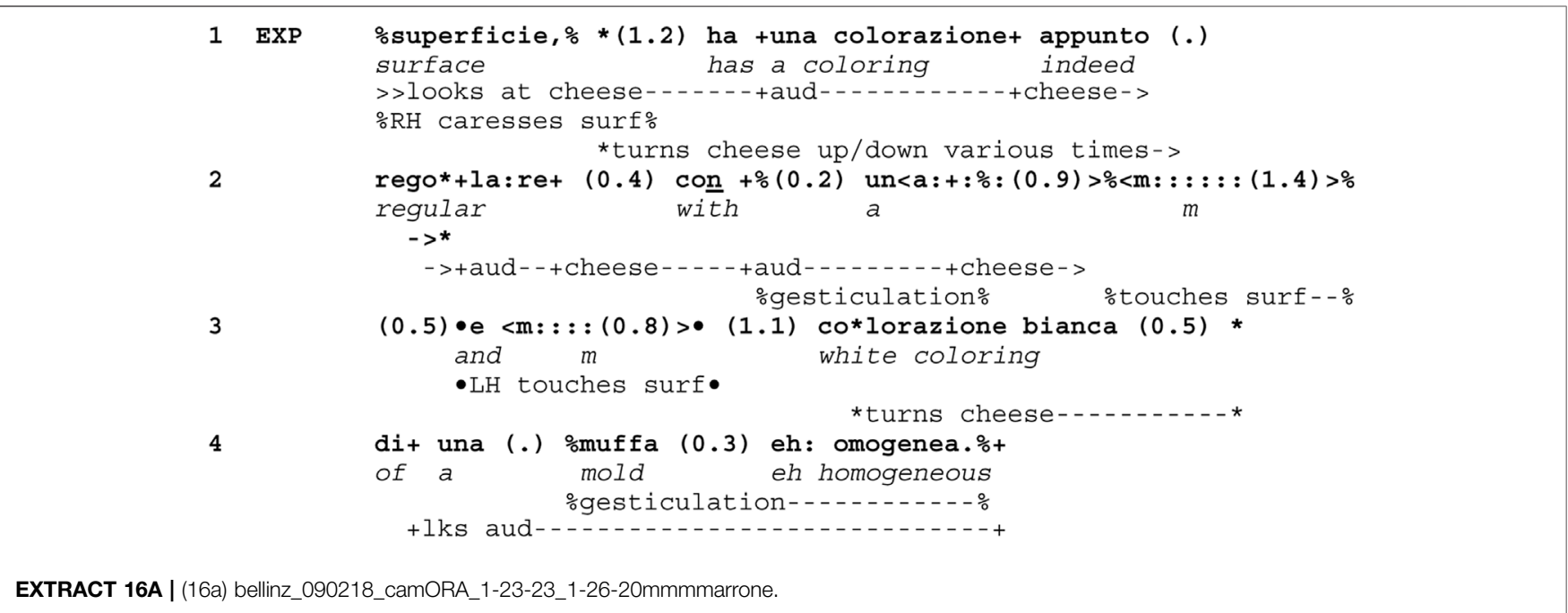


simplest format $\mathrm{N}+\mathrm{Adj}$ ) enables him to depart from the normative terminology and its order.

The fact that this puzzles the participants orienting to the terminology and the tasting sheet is observable in the subsequent extract, when they ask a question about the location of the descriptor (8) on the tasting sheet. Moreover, their suggested descriptors $(11-12,17)$ concerning the color are rejected or corrected by the expert. We first focus on the question (8) and the first collaborative suggestion (11) (Extract 16b).

The previous description (1-4) is brought to completion by the expert looking down at the computer (4). The multimodal completion of the description, this gaze shift, and the connective "allora"/"so" are oriented to by other participants as achieving a transition to the next item. In particular we focus on two participants, Biagio and Luigi, both sitting in the front row and both audible and visible in the video recording.

Like all the participants, Biagio is taking notes using the preformatted empty tasting sheet; he asks (8) where to write the previous description (and offers a candidate response, mentioning the "note"/"notes" rather than the "superficie"/"surface" section), displaying some disorientation relative to the procedure/ tasting sheet. The expert rejects the candidate response and rather indicates the "colore"/"color" section as relevant.

At the same time, just after "allora"/“so" (6), Luigi looks down at his terminology list (Figure 30) and looks up at the expert (Figure 31) only after the latter has produced the word "colore"/"color": at this point, Luigi immediately offers a possible descriptor (11) in a collaborative completion, in the form of a bare color adjective (also proposed by another participant, Franca, 12) i.e., in a format that corresponds to the standard terminology. When the expert, instead of ratifying this proposal, engages in a new clause beginning with the copula (14), projecting a more complex description of the color, Luigi looks back at his list, as if to make sense of it, and then looks back to the expert, listening and looking at his demonstration (14). He will write again only later on (Figure 35), only after the new description has mentioned the color "white" he was proposing earlier (see Extract 16c, 18).

So, Biagio and Luigi both display, albeit in different ways, a double orientation toward the ongoing demonstration and, at the same time, toward their written tools; their actions show alternative trajectories and anticipation with respect to the turn formatting of the expert. Nonetheless, the expert continues with a complex description, not making any use of the short descriptors proposed but using instead a more elaborated syntactical structure. In this way, he signals that the description is departing from the normative model at hand. The distinctiveness of this format is revealed again by his disalignment with Biagio proposing a descriptor selected from the list (17) (Extract 16c).

The complex turn of the expert $(14-15,18)$ displays some difficulty in describing the color of the "ba:se," which is produced by him by not only looking at the rind but also rubbing it several times on both surfaces (14) while he utters a prolonged sound " $\mathrm{m}$ " (14) (possibly a hesitation in the first case and the initial sound of "marrone" in the second case). Thus, the expert exhibits his color description as the result of an intense and prolongated multisensorial engagement with the object.
At this point, Biagio, who was intensively looking at the presenter (Figure 32), treats the complex description as complete and volunteers another descriptor (">non uniforme<" 17) while looking at the expert in front of him (Figure 33). This descriptor features in the terminology sheet after the list of colors: its location within the list corresponds to the sequential position at which Biagio proposes it, at the completion of the previous color description.

The expert ignores this contribution by not responding to it. Instead, he continues with a relative clause (18), tied back to the $\mathrm{N}$ "ba:se" (14), in which he mentions again the "colorazione (0.4) bianca" introduced previously. Biagio continues to look intensively, leaning aside to see better (Figure 34). As the expert mentions the color "bianca" (18), Luigi begins to write (Figure 35), and Biagio looks down at his notes too (Figure 36) while another participant repeats the color adjective (19).

The expert continues to look at the cheese, manipulating it while he inspects it for a long moment (20). The result of this examination is delivered in the final description (21-24), which contradicts Biagio's proposal, in a complete clause with copula (21), then corrected in an increment (22) and followed by another clause explaining the causes of the relative nonuniformity of the cheese's surface (22-24). The complex syntactic arrangement enables a gradual qualification of the "uniformity" of the white coloring, with "<abba>stanza"/fairly" (21), "non completamente"/"not entirely" (22), and "un pochettino"/"a bit" (23), all expressions that relativize the uniformity (but never align with Biagio's descriptor "non uniforme"/"not uniform" 17). During this description, Biagio consults the terminology list (Figure 37), looks back at the sample (Figure 38), and finally writes on his tasting sheet (Figure 39).

In this case, the elaborated syntactic formatting of the expert's description addresses the complexity of the object to be described, which is not reducible to the bare adjectives contemplated in the terminology list. This elaborated formatting is also grounded in the embodied multisensorial examination of the sample, which exhibits the complexity of the object and the task. Nonetheless, the participants continue to make sense of the description by reference to the documents they have been socialized to use for enhancing the analyticity of their sensorial examination. A series of disalignments shows the discrepancies between the expected standard description using the minimal format $\mathrm{N}+$ Adj and relying on the normative order of the rubrics in the tasting sheet on one hand and, on the other hand, a complex description using a more elaborated syntax within a complex multimodal gestalt exhibiting the complexity of the object and the multisensoriality of the task of describing it. This discrepancy, observable in the disalignments between the participants, shows the consequentiality of the selection of alternative syntactic formats as exhibiting different forms of accountability and expertise.

\section{DISCUSSION AND CONCLUSION}

The article has explored the indexical, contingent, emergent, and yet systematic relations between syntactic formats and embodied conducts in a complex ecology of action. It has demonstrated how the choice of recurrent syntactic formats is related to several 


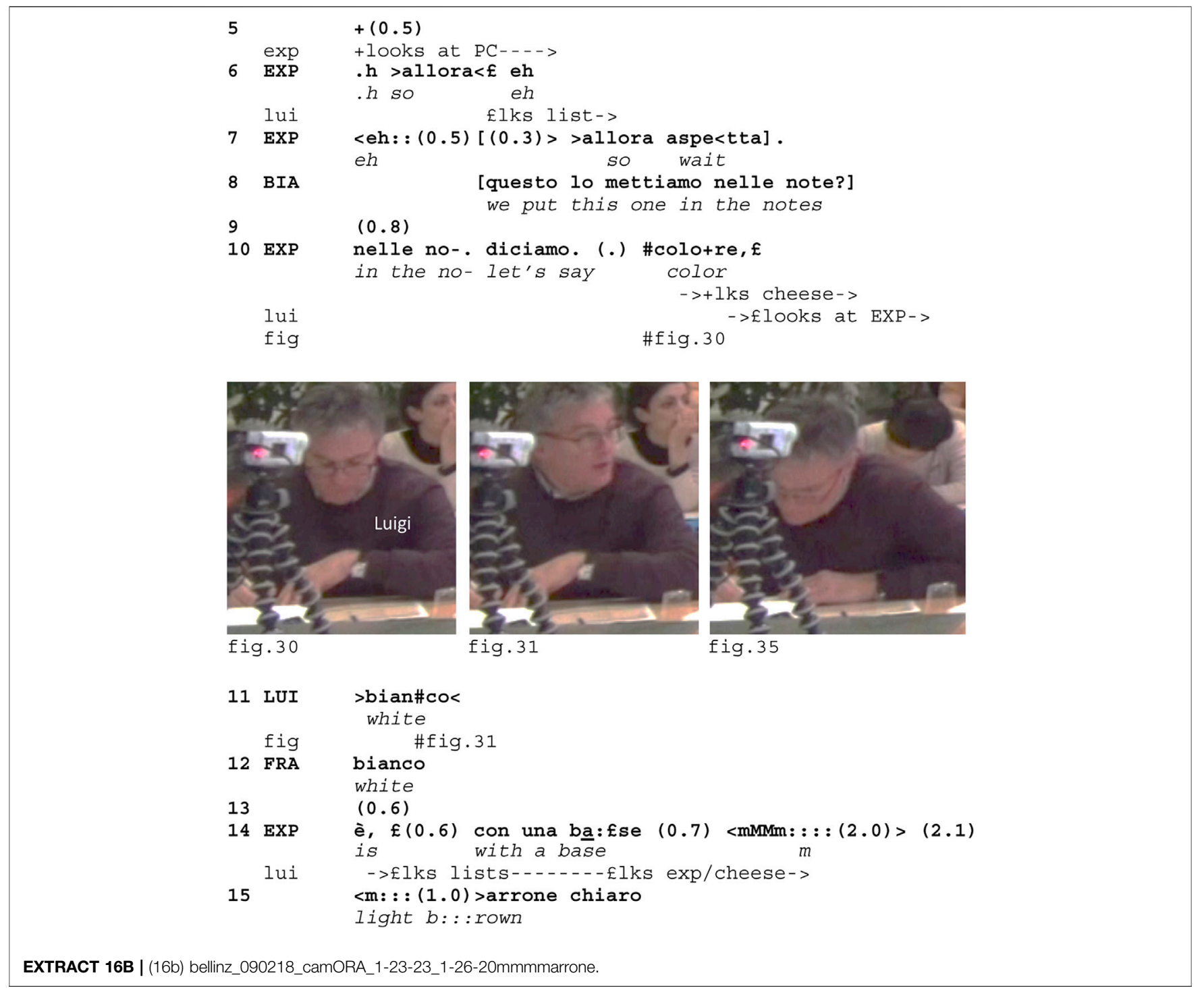

specific features of the ongoing activity and their methodic usage by the participants.

In the context studied-tasting sessions training professional cheese tasters-the simplest format $\mathrm{N}+$ Adj refers to the standard normative organization of the tasting lexicon, materialized in artifacts such as structured lists of technical descriptors and prestructured forms in which participants write tasting results. The use of this format also crucially refers to the sensorial activity of looking and touching (as well as smelling and tasting, see Mondada 2020b) the examined samples: each descriptor (in its standardized adjectival form) is produced as a result of a careful examination of the material object. This double orientation toward the semiotic artifacts (and the norms they represent) and toward the sensed object is embodied in the gaze toward screens and texts in the local ecology, alternating with practices of looking and touching the samples. Moreover, this double orientation is publicly witnessable and visibly exhibited for an audience of trainees learning how to sensorially experience and describe the objects at hand. Thus, the simplest format $\mathrm{N}+$ Adj (as well as its specific temporal realization) is deeply rooted in the local ecology, in which it not only reproduces a normative model but reflexively invites both expressing the senses and feeling the words.

The format $\mathrm{N}+$ Adj can be further expanded: the $\mathrm{N}$ and Adj can feature in a clause or in more elaborated syntactical constructions. The choice of these alternative formats depends on the complexity of the object as it is exhibited in the search for solutions/formulations by the speaker, displaying that it is impossible to merely apply existing terminologies. In these cases, the temporality of the description is characterized not only by visible long silent sensorial examinations of the object but also by stretched sounds and syllables making the process of elaborating a description audible. In these expanded and elaborated formats, the speaker often explicitly formulates the conditions and practices of saying and sensing.

These different multimodal formats for describing visual and haptic features of the object are adjusted to the temporality of 


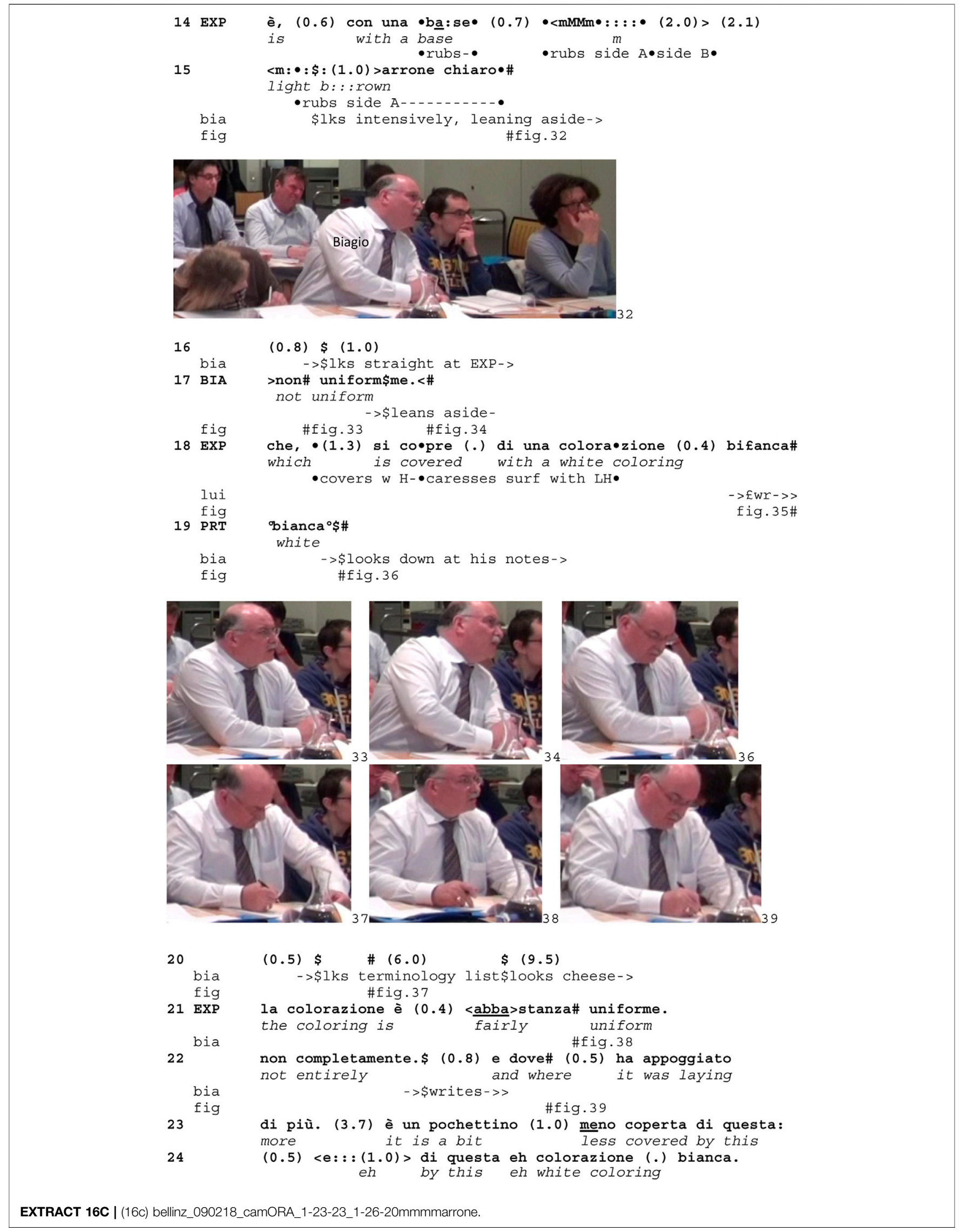


sensing them. As demonstrated elsewhere (Mondada 2018a, 2021), the formatting of "active sensing" (by analogy to "active touching," Gibson 1962) excludes talking. This is not only the case for tasting or sniffing, in which it is difficult to ingest or smell and at the same time speak, but is also the case for looking and touching, which in principle could be achieved while talking at the same time. This shows that the exclusion of talk is not merely caused by a physical impossibility but relates to ways of formatting the action going on: in the context of tasting, looking and touching are achieved silently by the taster displaying their total focus on the object. Only afterward do they verbally describe and comment on it. This temporal distribution also enables the speaker to display that the description is actually the outcome of their sensorial engagement (cf. Mondada 2020a for sniffing as providing for the publicly demonstrable sensorial ground for talking).

This temporal, embodied, and material distribution of silence vs. talk, and of sensing vs. talking within various syntactic-lexical formats shows how a conception of syntax in interaction inspired by multiactivity contributes to a better understanding of a situated syntax permeable to local contingencies and concurrent actions and, more generally, of the relations between body and grammar, sensoriality, and language. The latter have been discussed from a lexical, semantic, and cognitive perspective on the senses, abundantly addressed in neurocognitive, and psycholinguistic studies (Majid 2021), but have not yet been discussed in relation to the in situ and in vivo choice of syntactic formats articulated with embodied practices of manipulating samples, making them accessible to the eyes or the hands (as well as the nose and the mouth, Mondada 2020b). Speakers' use of syntax reveals finely tuned orientations toward the details in which the world is visually and haptically (olfactorily and gustatively) explored and ultimately toward how the senses enable the production of its linguistic description.

In turn, this focus on specific situated constraints on syntactic formats highlights the flexibility, variability, and also the systematicity of syntax as it is locally used, adjusted, and reshaped by the speakers. This approach of the indexicality of syntax shows how it is deeply embedded in the specificity of its situated activity and its material ecology. It also shows the importance of considering peculiar formats tailored for/by the activity at hand and the systematicity of their use, revealing how speakers methodically orient to their differences and distributions as relevant and meaningful within that activity.

\section{REFERENCES}

\section{De Stefani, E. This SI.}

Deppermann, A. (2013a). Turn-design at Turn-Beginnings: Multimodal Resources to deal with Tasks of Turn-Construction in German. J. Pragmatics 46, 91-121. doi:10.1016/j.pragma.2012.07.010

Deppermann, A. (Editor) (2013b). "Multimodal Interaction from a Conversation Analytic Perspective,". Spec. Issue. J. Pragmatics 46, 1-7. doi:10.1016/.jpragma.2012.11.014

Deppermann, A. and Streeck, J. (Editors) (2018). Time in Embodied Interaction (Amsterdam: Benjamins).

Drake, M. A., and Civille, G. V. (2003). Flavor Lexicons. Comp. Rev. Food Sci. Food Saf. 2 (1), 33-40. doi:10.1111/j.1541-4337.2003.tb00013.x

\section{Transcript Conventions}

Talk has been transcribed following Jefferson's conventions (2004) and embodiment following Mondada's conventions (2018a; see https:/www.lorenzamondada.net/multimodal-transcription).

\section{DATA AVAILABILITY STATEMENT}

The original contributions presented in the study are included in the article, further inquiries can be directed to the corresponding author.

\section{ETHICS STATEMENT}

Ethical review and approval was not required for the study on human participants in accordance with the local legislation and institutional requirements. The patients/participants provided their written informed consent to participate in this study. Written informed consent was obtained from the individual(s) for the publication of any potentially identifiable images or data included in this article.

\section{AUTHOR CONTRIBUTIONS}

The Author collected alone the data from Bellinzona, and with Giolo Fele the data from Trento. She did the transcripts, elaborated the theoretical background and the analysis, and wrote the article.

\section{FUNDING}

Research reported in the paper was supported by the project From multimodality to multisensoriality: Language, Body, and Sensoriality in Social Interaction (intSenses) funded by the Swiss National Science Foundation (project number 100012_175969) of which the Author is the P.I.

\section{ACKNOWLEDGMENTS}

I warmly thank the participants to the tasting sessions in Bellinzona and Trento, as well as the organizers, for having accepted to be recorded.

Evans, B., and Reynolds, E. (2016). The Organization of Corrective Demonstrations Using Embodied Action in Sports Coaching Feedback. Symbolic Interaction 39 (4), 525-556. doi:10.1002/symb.255

Fele, G. (2019). "10. Olfactory Objects: Recognizing, Describing and Assessing Smells during Professional Tasting Sessions," in Objects, Bodies and Work Practice. Editors D. Day and J. Wagner (Bristol: Multilingual Matters), 250-284. doi:10.21832/9781788924535-013

Ford, C. E., Thompson, S. A., and Drake, V. (2012). Bodily-visual Practices and Turn Continuation. Discourse Process. 49, 192-212. doi:10.1080/ 0163853x.2012.654761

Gibson, J. J. (1962). Observations on Active Touch. Psychol. Rev. 69 (6), 477-491. doi: $10.1037 / \mathrm{h} 0046962$

Goffman, E. (1978). Response Cries. Language 54, 787-815. doi:10.2307/413235 
Gonzalez Temer, V. (2017). A Multimodal Analysis of Assessment Sequences in Chilean Spanish Interaction. York: University of York. PhD thesis.

Goodwin, C. (1981). Conversational Organization. New York: Academic Press.

Goodwin, C., and Goodwin, M. H. (1987). Concurrent Operations on Talk. IPrAPiP 1 (1), 1-54. doi:10.1075/iprapip.1.1.01goo

Goodwin, C. (1994). Professional Vision. Am. Anthropologist 96 (3), 606-633. doi:10.1525/aa.1994.96.3.02a 00100

Goodwin, M. H., and Goodwin, C. (2012). Car Talk: Integrating Texts, Bodies, and Changing Landscapes. Semiotica 191, 257-286. doi:10.1515/sem-2012-0063

Haddington, P., Keisanen, T., Mondada, L., and Nevile M. (Editors) (2014). Multiactivity in Social Interaction (Amsterdam: Benjamins).

Hayashi, M. (2005). Joint Turn Construction through Language and the Body: Notes on Embodiment in Coordinated Participation in Situated Activities. Semiotica 2005, 21-53. doi:10.1515/semi.2005.2005.156.21

Heath, C. (1989). Pain Talk: The Expression of Suffering in the Medical Consultation. Soc. Psychol. Q. 52, 113-125. doi:10.2307/2786911

Hepburn, A. (2004). Crying: Notes on Description, Transcription, and Interaction. Res. Lang. Soc. Interaction 37 (3), 251-290. doi:10.1207/ s15327973rlsi3703_1

Jefferson, G. (1985). "An Exercise in the Transcription and Analysis of Laughter,". Handbook of Discourse Analysis. Editor T. A. van Dijk (London: Academic Press), Vol. 3, 25-34.

Jefferson, G. (2004). "Glossary of Transcript Symbols with an Introduction," in Conversation Analysis: Studies from the First Generation. Editor G. H. Lerner (Amsterdam: Benjamins), 13-31. doi:10.1075/pbns.125.02jef

Keevallik, L., and Ogden, R. (2020). Sounds on the Margins of Language at the Heart of Interaction. Res. Lang. Soc. Interaction 53 (1), 1-18. doi:10.1080/ 08351813.2020 .1712961

Keevallik, L. (2013). The Interdependence of Bodily Demonstrations and Clausal Syntax. Res. Lang. Soc. Interaction 46 (1), 1-21. doi:10.1080/ 08351813.2013.753710

Keevallik, L. (2018a). "The Temporal Organization of Conversation while Mucking Out a Sheep Stable,". Time in Embodied Interaction: Synchronicity and Sequentiality of Multimodal Resources. Editors A. Deppermann and J. Streeck (Amsterdam: Benjamins), 97-122.

Keevallik, L. (2014). Turn Organization and Bodily-Vocal Demonstrations. J. Pragmatics 65, 103-120. doi:10.1016/j.pragma.2014.01.008

Keevallik, L. (2018b). What Does Embodied Interaction Tell Us about Grammar. Res. Lang. Soc. Interaction 51 (1), 1-21. doi:10.1080/ 08351813.2018.1413887

Kendon, A. (2004). Gesture: Visible Action as Utterance. Cambridge: CUP.

Laurier, E., Lorimer, H., Brown, B., Jones, O., Juhlin, O., Noble, A., et al. (2008). Driving and 'Passengering': Notes on the Ordinary Organization of Car Travel. Mobilities 3 (1), 1-23. doi:10.1080/17450100701797273

Levinson, S. C., and Majid, A. (2014). Differential Ineffability and the Senses. Mind Lang. 29 (4), 407-427. doi:10.1111/mila.12057

Liberman, K. (2013). "The Phenomenology of Coffee Tasting," in More Studies in Ethnomethodology. Editor K. Liberman (New York: SUNY), 215-266.

Majid, A. (2021). Human Olfaction at the Intersection of Language, Culture, and Biology. Trends Cogn. Sci. 25 (2), 111-123. doi:10.1016/ j.tics.2020.11.005

Mondada, L. (2020a). Audible Sniffs: Smelling-In-Interaction. Res. Lang. Soc. Interaction 53 (1), 140-163. doi:10.1080/08351813.2020.1716592

Mondada, L. (2019a). Contemporary Issues in Conversation Analysis: Embodiment and Materiality, Multimodality and Multisensoriality in Social Interaction. J. Pragmatics 145, 47-62. doi:10.1016/.pragma.2019.01.016

Mondada, L. (2014c). "Cooking Instructions and the Shaping of Things in the Kitchen," in Interacting with Objects: Language, Materiality, and Social Activity. Editors M. Nevile, P. Haddington, T. Heinemann, and M. Rauniomaa (Amsterdam: Benjamins), 199-226. doi:10.1075/z.186.09mon

Mondada, L., and Fele, G. (2020). Descrittori visivi per l'assaggio professionale: lessico, sensorialità e standardizzazione. Rivista Italiana di Linguistica Applicata XLIX (3), 651-681.

Mondada, L. (2020b). Orchestrating Multi-sensoriality in Tasting Sessions: Sensing Bodies, Normativity, and Language. Symbolic Interaction 44, 63-86. doi:10.1002/symb.472

Mondada, L. (2019b). "Rethinking Bodies and Objects in Social Interaction: a Multimodal and Multisensorial Approach to Tasting," in Discussing New
Materialism: Methodological Implications for the Study of Materialities. Editors U. Tikvah Kissmann and J. van Loon (Berlin: Springer), 109-134. doi:10.1007/978-3-658-22300-7_6

Mondada, L. (2021). Sensing in Social Interaction. Cambridge: CUP.

Mondada, L. (2012). Talking and Driving: Multiactivity in the Car. Semiotica 191, 223-256. doi:10.1515/sem-2012-0062

Mondada, L. (2014a). The Local Constitution of Multimodal Resources for Social Interaction. J. Pragmatics 65, 137-156. doi:10.1016/ j.pragma.2014.04.004

Mondada, L. (2009). The Methodical Organization of Talking and Eating: Assessments in Dinner Conversations. Food Qual. Preference 20 (8), 558-571. doi:10.1016/j.foodqual.2009.03.006

Mondada, L. (2018a). The Multimodal Interactional Organization of Tasting: Practices of Tasting Cheese in Gourmet Shops. Discourse Stud. 20 (6), 743-769. doi:10.1177/1461445618793439

Mondada, L. (2011). "The Organization of Concurrent Courses of Action in Surgical Demonstrations," in Embodied Interaction: Language and Body in the Material World. Editors J. Streeck, C. Goodwin, and C. LeBaron (Cambridge: CUP), 207-226.

Mondada, L. (2014b). "The Temporal Orders of Multiactivity," in Multiactivity in Social Interaction. Editors P. Haddington, T. Keisanen, L. Mondada, and M. Nevile (Amsterdam: Benjamins), 33-76. doi:10.1075/z.187.02mon

Mondada, L. (2018b). "Visual Practices: Video Studies, Multimodality and Multisensoriality," in Co-operative Engagements in Intertwined Semiosis: Essays in Honour of Charles Goodwin. Editor D. Favareau (Tartu: University of Tartu Press), 304-325.

Nevile, M. (2018). Configuring Materiality, Mobility, and Multiactivity: Interactions with Objects in Cars. Si 1 (1). doi:10.7146/si.v1i1.105497

Nishizaka, A. (2014). Instructed Perception in Prenatal Ultrasound Examinations. Discourse Stud. 16, 217-246. doi:10.1177/1461445613515354

Nishizaka, A. (2016). Syntactical Constructions and Tactile Orientations: Procedural Utterances and Procedures in Massage Therapy. J. Pragmatics 98, 18-35. doi:10.1016/j.pragma.2016.04.004

Nishizaka, A. (2017). The Perceived Body and Embodied Vision in Interaction. MindCult. Activity 24 (2), 110-128. doi:10.1080/10749039.2017.1296465

Pomerantz, A. (1984). "Agreeing and Disagreeing with Assessments: Some Features of Preferred/dispreferred Turn Shapes," in Structures of Social Action: Studies in Conversation Analysis. Editors J. M. Atkinson and J. Heritage (Cambridge: CUP), 57-101.

Råman, J., and Haddington, P. (2018). Demonstrations in Sports Training: Communicating a Technique through Parsing and the Return-Practice in the Budo Class. Multimodal Commun. 7 (2), 1-19. doi:10.1515/mc-20180001

Rossano, F. (2012b). "Gaze in Conversation," in The Handbook of Conversation Analysis. Editors J. Sidnell and T. Stivers (Malden: Wiley-Blackwell), 308-329. doi:10.1002/9781118325001.ch15

Rossi, G. (2012). Bilateral and Unilateral Requests: The Use of Imperatives andMi X?Interrogatives in Italian. Discourse Process. 49 (5), 426-458. doi:10.1080/ 0163853x.2012.684136

Schegloff, E. A. (1984). "On Some Gestures' Relation to Talk," in Structures of Social Action: Studies in Conversation Analysis. Editors J. M. Atkinson and J. Heritage (Cambridge: Cambridge University Press), 266-295.

Sorjonen, M.-L., and Raevaara, L. (2014). "On the Grammatical Form of Requests at the Convenience Store," in Requesting in Social Interaction. Editors P. Drew and E. Couper-Kuhlen (Amsterdam: Benjamins), 243-268. doi:10.1075/ slsi.26.10sor

Stivers, T., and Rossano, F. (2010). Mobilizing Response. Res. Lang. Soc. Interaction 43 (1), 3-31. doi:10.1080/08351810903471258

Streeck, J., Goodwin, C., and LeBaron, C. (Editors) (2011). Embodied Interaction: Language and Body in the Material World (Cambridge: Cambridge University Press).

Stukenbrock, A. (2017). "Intercorporeal Phantasms: Kinestheric Alignment with Imagined Bodies in Self-Defense Training," in Intercorporeality: Emerging Socialities in Interaction. Editors C. Meyer, J. Streeck, and J. S. Jordan (Oxford: Oxford University Press), 237-265.

Weatherall, A. (2021). "Displaying Emotional Control by How Crying and Talking Are Managed," in How Emotions Are Made in Talk. Editors J. S. Robies and A. Weatherall (Amsterdam/Philadelphia: Benjamins). 
Wiggins, S. (2014). Adult and Child Use of Love, like, Don't like and Hate during Family Mealtimes. Subjective Category Assessments as Food Preference Talk. Appetite 80 (1), 7-15. doi:10.1016/j.appet.2014.04.024

Wiggins, S., and Potter, J. (2003). Attitudes and Evaluative Practices: Category vs. Item and Subjective vs. Objective Constructions in Everyday Food Assessments. Br. J. Soc. Psychol. 42 (4), 513-531. doi:10.1348/014466603322595257

Wiggins, S. (2002). Talking with Your Mouth Full: Gustatory Mmms and the Embodiment of Pleasure. Res. Lang. Soc. Interaction 35 (3), 311-336. doi:10.1207/s15327973rlsi3503_3

Conflict of Interest: The author declares that the research was conducted in the absence of any commercial or financial relationships that could be construed as a potential conflict of interest.
Publisher's Note: All claims expressed in this article are solely those of the authors and do not necessarily represent those of their affiliated organizations, or those of the publisher, the editors and the reviewers. Any product that may be evaluated in this article, or claim that may be made by its manufacturer, is not guaranteed or endorsed by the publisher.

Copyright (C) 2021 Mondada. This is an open-access article distributed under the terms of the Creative Commons Attribution License (CC BY). The use, distribution or reproduction in other forums is permitted, provided the original author(s) and the copyright owner(s) are credited and that the original publication in this journal is cited, in accordance with accepted academic practice. No use, distribution or reproduction is permitted which does not comply with these terms. 